\title{
Optimal Operation for Regional IES Considering the Demand- and Supply-Side Characteristics
}

\author{
Wenying Li, Ming Tang, Xinzhen Zhang * ${ }^{\mathbb{D}}$, Danhui Gao and Jian Wang
}

check for updates

Citation: Li, W.; Tang, M.; Zhang, X.; Gao, D.; Wang, J. Optimal Operation for Regional IES Considering the

Demand- and Supply-Side

Characteristics. Energies 2022, 15,

1594. https://doi.org/10.3390/ en15041594

Academic Editor: Javier Contreras

Received: 22 December 2021

Accepted: 17 February 2022

Published: 21 February 2022

Publisher's Note: MDPI stays neutral with regard to jurisdictional claims in published maps and institutional affiliations.

Copyright: (C) 2022 by the authors. Licensee MDPI, Basel, Switzerland. This article is an open access article distributed under the terms and conditions of the Creative Commons Attribution (CC BY) license (https:// creativecommons.org/licenses/by/ $4.0 /)$.
Sichuan Energy Internet Research Institute, Tsinghua University, Chengdu 610042, China; liwenliang@163.com (W.L.); tangming@163.com (M.T.); danhuigao@163.com (D.G.); jianwnag@163.com (J.W.)

* Correspondence: wenyingli_tseiri@163.com

\begin{abstract}
A regional integrated energy system (RIES) is an electricity-centric multi-energy system that can realize the mutual conversion of electricity, heat, cold, and other energy. Through multiflexible resource interaction and the transaction of multi-investment entities, the efficiency of energy utilization can be improved. To systematize energy-consuming entities and scale photovoltaic-based renewable energy in a distribution network, the energy-consuming behavior, energy-producing schedule, and trading strategy can be coupled. Considering the interaction between the energyconsuming behavior and the uncertainty of distributed photovoltaic output, an optimal operation method for RIES is proposed on the basis of social network theory and an uncertain evolutionary game method in this paper. From the perspective of the operator, the overall profits of RIES are maximized considering the entity characteristics of both the demand and the supply side. A case study shows that the proposed method can ensure the reasonable distribution of profit among the investment entities. A closer social relationship between energy-consuming entities or a lower transaction risk cost of energy-producing entities can increase the overall energy transaction profit.
\end{abstract}

Keywords: regional integrated energy system; social network theory; uncertain evolutionary game; energy transaction strategy

\section{Introduction \\ 1.1. Motivation}

With the increasing energy consumption worldwide, traditional energy is facing a severe situation. The establishment of a multi-energy coupling system, breaking the independent operation mode of each energy source, has become an urgent need for sustainable development. Thus, integrated energy system (IES) technology has gradually been developed and valued [1,2]. Electrical energy is the core of the IES, which can realize the mutual conversion of electricity, heat, cold, and other sources of energy, as well as the flexible distribution of multiple types of consumption and the optimized coordination of multiple market entities. It can also effectively improve the energy utilization efficiency and play an important role in sustainable energy systems [3,4].

According to the supply range, voltage level, and device capacity, IESs can be divided into community integrated energy systems (CIESs) and regional integrated energy systems (RIESs) [5]. RIESs provide integrated energy services for energy suppliers and users within a certain area, which is composed of multiple CIESs. With a $10 \mathrm{kV}$ medium-voltage distribution network (DN) as the physical framework, the load capacity is typically 5-10 MW. RIESs include multiple energy sources such as distributed wind power, distributed photovoltaic (PV) power, and a combined heat and power (CHP) unit [6]. RIES users conduct integrated energy transactions with the energy operator to flexibly meet the needs of users for multiple types of loads such as electricity, heat, and cold. The RIES operator optimizes energy production plans and rationally allocates energy transmission ratios on the basis of load levels and energy market conditions to expand total benefits and improve system 
efficiency [7]. With the increased market share of RIESs, multi-energy coupling and the co-supply of multiple consumers are achievable [8]. To balance the interests of all parties, promote optimized operation, and produce overall benefits, it is necessary to formulate an energy operation plan, which is suitable for RIESs to achieve the benign guidance of the energy usage and transaction behavior of each entity.

\subsection{Previous Work}

Previous research has mainly focused on the design of IES energy transaction models and operation frameworks, through combinations with energy hubs (EHs), CHP units, energy storage systems (ESSs), electrical vehicles, demand response, and distributed PV technologies. One study designed a benefit distribution method using game methods, so as to establish a multi-energy complementary and win-win-oriented energy management scheme [9]. A community energy transaction rule was proposed in [10], which combines electrical vehicles with RIES energy transactions to fully utilize the dispatch potential of electric vehicles and controllable loads. The authors of [11] considered the impact of a demand-side ESS in energy transactions, and they proposed a transaction strategy to maximize the interests of all parties based on noncooperative game theory. Using evolutionary game theory, and considering the transaction strategy formulation of irrational users affected by other users, an evolutionary game model for user behaviors and RIES transaction rules was established in [12]. To minimize the power purchase cost of users, the bilateral contract transaction mode between suppliers and large users based on the theory of a master-slave game was studied in [13]. An optimal energy allocation method to reduce energy cost driven by the price mechanism was proposed using the interactive game model of multiple comprehensive load aggregators in [14].

From the energy demand side, the number of participants in various energy transactions has gradually increased, increasing the difficulty of coordinating the behavior of various entities and balancing the interests of all parties [15]. Furthermore, the energy interconnection between entities can be realized through sharing or trading, and individual users can be combined into an organically linked whole to improve energy efficiency and utilization. Therefore, it is necessary to consider the impact on energy sharing and adjust the transaction strategy between users, as well as study effective energy transaction models to optimize energy-consuming behavior. An energy transaction mechanism under the multi-buyer multi-seller situation based on the Stackelberg game was proposed in [16], which could improve the local consumption of renewable energy and the energy utilization efficiency. The authors of [17] established an electricity cost model associated with system net load, which provided the optimal electricity consumption arrangement of PV aggregated users. A day-ahead power flow optimization method implementing distributed PV, CHP, and ESS was proposed in [18] to minimize the total cost of an RIES. In summary, energy management schemes suitable for multi-energy mixed users have been presented in the literature according to consumption characteristics. However, the above research only considered the relationship between suppliers and users in the RIES, while ignoring the influence of the social relationship between users with respect to energy transaction rules. Energy users are not isolated individuals, and there are often strong social relationships among them in an RIES; these social relationships have a great impact on all aspects of user behavior [19]. User groups have high social agglomeration, and the social relationships between users exhibit universality, diversity, and long-term effectiveness. The social network relationships between users affect load curves, energy purchase costs, transaction decisions, etc. Therefore, it is necessary to consider the impact on user social networks of energy transactions in an RIES to formulate energy transaction and management mechanisms suitable for high-density user energy communities.

From the energy supply side, the penetration rate of renewable energy such as distributed PV has gradually increased. Despite injecting cleaner energy into the RIES, it brings more uncertain factors for the operation and scheduling of the system. Due to the volatility of renewable energy, its large-scale integration may affect the production 
plans and trading strategies of transaction entities. Therefore, the energy management mechanism of an RIES needs to consider the uncertainty of the energy supply side, while protecting the interests of the entities, as well as the safety and economical operation of the system. Due to the influence of external random factors such as the weather, temperature, and sunshine intensity, the actual output of renewable energy may deviate from the expected value, which will affect the energy purchase/sale strategies and energy-consuming plans of supplies and users. The authors of [20] summarized the morphological evolution of the power system under temporal and spatial uncertainty, and they pointed out that the traditional forecasting and planning methods can be changed to solve the problems related to planning and reliable operation faced by the large-scale integration of renewable energy into grid. The error indices and a segment exponential distribution model for wind power prediction were established in [21], where the nonlinear least square method was utilized to estimate the error parameters of wind power output. The probability distribution characteristics of discrete random variables were used to describe the uncertainty of PV output under different weather conditions based on meteorological data in [22]. On the basis of the real-time dispatching effective steady-state safe area method and a linear power flow model, a real-time voltage dispatch model was proposed to realize the safe and economic operation of an RIES using the robust optimization method [23]. Due to the multi-energy coupling and multi-network interconnection mechanisms in an energy transaction process, each entity needs to comprehensively consider the capital loss caused by the uncertainty and amplitude of the output fluctuation, before formulating the optimal plan and transaction strategy. Therefore, it is necessary to further study the possible risk costs of renewable energy output in the energy transaction process of each entity.

\subsection{Current Contribution}

Considering the joint influence of the uncertainty of the energy supply side and the coupling of the energy demand side to the energy transaction and optimal operation of the RIES, the social network theory and uncertain evolutionary game method are applied in this paper to formulate an optimal operation strategy for an RIES. We analyze the entity characteristics of the demand and supply side, as well as maximize the overall operation profit from the perspective of the RIES operator, while also considering the energy sharing in a lower-level CIES. The main contributions are as follows:

(1) An alliance strategy for energy-consuming entities in a CIES is proposed on the basis of social network theory, which can simplify the number of transaction objects while considering the coupling relationship on the demand side.

(2) A distributed PV output characteristic model based on the uncertain evolutionary game method is constructed, which fully considers the risk cost on the supply side and the impact of the uncertainty output on the trading strategy.

(3) Considering the uncertainty of distributed photovoltaic output and the energyconsumption interactions, an optimal operation method for RIES based on social network theory and the uncertain evolutionary game method is proposed in this paper.

(4) A case study is carried out for an RIES consisting of three CIESs; the results show that the proposed method can ensure a reasonable distribution of benefits for each participant, while having great significance for optimizing the energy composition and promoting the local consumption of renewable energy.

\subsection{Structure}

The remainder of this paper is organized as follows: Section 2 presents the energyconsumption model based on social network theory. Section 3 builds the distributed PV output characteristic model based on uncertain evolutionary games. On this basis, Section 4 constructs the operating profit model of demand-side entities, supply-side entities, and the RIES operator, and the optimal operation strategy for the RIES is also proposed. The case study is carried in Section 5, while Section 6 concludes the paper. 


\section{Characteristic Modeling of Community Energy-Consuming Entities Based on Social Network Theory}

\subsection{Social Network Theory}

Social network theory mainly studies the social relationships, individual behaviors, and interactions among individuals. The social network model based on complex network theory can be represented by a network topology composed of nodes and edges. Each node represents an individual member, whereas the edges between nodes represent the familiarity between members. Social networks can be expressed as $S N(U, E, R)$, where $U$, $E$, and $R$ are the nodes, edges, and weights respectively, and the weight values denote the familiarity among members. There are interactions among individuals in a social network, whereby the social activities of some individuals are changed by the social activities of other individuals. In order to describe the degree of collaboration of social behavior among individuals, user similarity was defined in [24], representing the probability of collaborative social behavior between users $v$ and $u$ as a function of the degree of familiarity among members.

$$
T_{v u}=\frac{R_{v u}}{\sqrt{\sum_{l \in V} R_{l v} \sum_{k \in U} R_{k u}}},
$$

where $R_{v u}$ is the familiarity between nodes $v$ and $u$ (if two nodes are not adjacent, $R_{v u}=0$ ); $V, U$ represent the sets of adjacent nodes $v$ and $u$, respectively.

The PageRank algorithm [25] is used to calculate the potential influence of each vertex in the network as a function of the mutual degree of users. The PageRank algorithm is based on the idea that a browser randomly browses webpages, thus obtaining the browsing probability for each webpage. The algorithm uses the transition matrix to repeatedly multiply the initial probability distribution vector until it converges to the limit probability distribution. This convergence limit is the browsing probability of the browser for each webpage. Since random web browsing is a typical Markov process, the algorithm can converge into a strongly connected graph without a termination point. Therefore, in a social network model, the PageRank algorithm can be used to calculate the transition matrix $M$ on the basis of Equation (1).

$$
M_{v u}= \begin{cases}\frac{T_{v u}}{\sum_{l \in \mathrm{U}} T_{l u}} & \text { node } v, u \text { is adjacent } \\ 0 & \text { others }\end{cases}
$$

Then, the transition matrix $M$ can be used to repeatedly multiply the initial probability distribution vector, whereby its convergence limit can be used as the potential influence vector $W$ of each vertex in the social network model. Therefore, on the basis of the familiarity between individuals, the similarity between individuals can be calculated, and then the transition matrix can be obtained, while the individual influence matrix can be obtained through the PageRank algorithm. The individual influence can be used to calculate the strength of influence between individuals, and then the social network can be realized on the basis of this strength.

\subsection{Alliance Strategy for Community Energy-Consuming Entities}

The translational load ratio can be defined as the initial probability distribution vector $\mathrm{Ra}$ in the PageRank algorithm.

$$
R a_{i}=\frac{L_{\mathrm{s} i}}{\sum_{i} L_{\mathrm{s} i}},
$$

where $L_{s i}$ is the shiftable load (SL) of user $i$. SL refers to the freely disposable load that can be adjusted according to the electricity price or demand in different periods to optimize their interests, such as the use of a washing machine, electric vehicle, etc.

In an energy transaction, SL is the main bargaining chip for users when participating in the market game [26]; therefore, the proportion of SL can reflect the initial weight of 
individual users in the energy transaction market. According to the potential influence $W$ and user similarity $T_{v u}$, the influence of users can be calculated as follows [24]:

$$
\begin{gathered}
W=\lim _{n \rightarrow+\infty} M^{n} \cdot R a, \\
W_{v u}=\frac{\left(W_{v}+W_{u}\right) T_{v u}}{2},
\end{gathered}
$$

where $W_{i}$ is the potential influence of individual user $i$ in the social network; $W_{v u}$ is the ability of users to interact with each other and reflects the closeness of users involved in energy transactions.

The Fast Newman (FN) algorithm [27] is used to divide the community users as a function of the relationship weight. Users in the alliance can mutually adjust SL according to the electricity price information and the actual electricity consumption to maximize the overall benefits of the alliance. According to the characteristics of social networks, modularity $\mathrm{Q}$ is defined as follows:

$$
\begin{gathered}
Q=\frac{1}{2 m} \sum_{i j}\left[W_{i j}-\frac{k_{i} k_{j}}{2 m}\right] \delta(i, j), \\
\left\{\begin{array}{l}
m=\frac{1}{2} \sum_{i j} W_{i j} \\
k_{i}=\sum_{j} W_{i j} \\
\delta(i, j)=\left\{\begin{array}{l}
1 i, j \text { belongs to same community } \\
0 \text { others }
\end{array}\right.
\end{array}\right.
\end{gathered}
$$

where $m$ is the sum of all edge weights (i.e., the sum of influence between users), $k_{i}$ is the sum of edge weights of node $i$ (i.e., the sum of influence between user $i$ and other users), $\delta(i, j)$ is a binary variable, which characterizes whether nodes $i$ and $j$ are grouped into the same community, and the modularity $Q$ can reflect the closeness of the community as a function of the influence between users.

The FN algorithm starts with a single user as a community. The two communities that produce the maximum value are then merged in each iteration until all users are merged into one community, and the value generated in each iteration is recorded. The iterative round of the largest value is selected as the optimal result; on the basis of this result, users in the same community are regarded as energy transaction alliances.

\section{Characteristic Modeling of Distributed Photovoltaic Output Based on Uncertain Evolutionary Game}

\subsection{Uncertain Evolutionary Game}

Due to the incomplete cognitive information in the game environment, its use to model humanity is not sufficiently rational. Furthermore, the natural environment is difficult to accurately predict, thus affecting the decision making and game benefits of participants. In a game environment with uncertain factors, the traditional game method has incomplete information on the game environment; therefore, stable parameters and fully rational settings of the decision-making entity are no longer applicable.

Uncertain game theory studies the game process under the influence of uncertain environmental factors. It requires players in each game to maximize their own profits according to various uncertain variables that may appear, while they are not affected by changes in uncertain factors. This strategy condition is consistent with the robust optimization method, and its game model can be described as follows: 


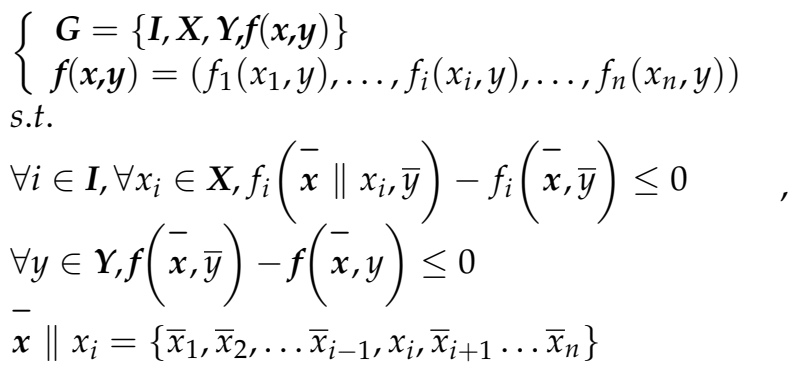

where $I$ is the set of players in the game, $X$ is the strategy set, $\boldsymbol{Y}$ is the set of uncertain parameters, and $f(x, y)$ is the profit function set. $f_{i}\left(x_{i}, y\right)$ indicates that, when the uncertain parameter is $y$, the profit of player $i$ can be achieved by adopting the strategy $x_{i} ;(\bar{x}, \bar{y})$ is the game equilibrium point, and $\bar{x} \| x_{i}$ indicates that the player $i$ has chosen strategy $x_{i}$, while the strategies of the other players remain $\bar{x}$.

After the player decides strategy $\bar{x}$ for uncertain parameters $\bar{y}$ of the equilibrium point according to Equation (8), any change in strategy will damage the player's profit, but not the uncertain parameters. When searching $(\bar{x}, \bar{y})$, all possible values of parameter $\bar{y}$ are sampled. If the value range of the uncertain factor $\boldsymbol{Y}$ is too large, the process is time-consuming. Therefore, this paper adds a virtual game player "disturber" to introduce a Nash equilibrium point into Equation (8), thus transforming the uncertain game into a deterministic game. The specific process is described below.

The $(n+1)$-th player is added to Equation (8) as follows:

$$
\begin{aligned}
& f_{n+1}\left(x_{n+1}\right)=-\left[f_{1}\left(x_{1}, y\right), f_{2}\left(x_{2}, y\right) \ldots f_{n}\left(x_{n}, y\right)\right]^{T}, \\
& x_{n+1}=y \in Y \\
& \quad f(\bar{x}, \bar{y})-f(\bar{x}, y) \leq 0 \\
& \quad \Rightarrow-\left[f_{1}\left(\bar{x}_{1}, y\right), f_{2}\left(\bar{x}_{2}, y\right) \ldots f_{n}\left(\bar{x}_{n}, y\right)\right]^{T} \\
& \quad-\left(-\left[f_{1}\left(\bar{x}_{1}, \bar{y}\right), f_{2}\left(\bar{x}_{2}, \bar{y}\right) \ldots f_{n}\left(\bar{x}_{n}, \bar{y}\right)\right]^{T}\right) \leq 0 \\
& \quad \Rightarrow f_{n+1}(y)-f_{n+1}(\bar{y}) \leq 0
\end{aligned}
$$

The Nash equilibrium point condition can then be written as

$$
\begin{array}{ll}
\boldsymbol{I}^{\prime}= & \{1,2, \ldots, n+1\}, \\
\boldsymbol{X}^{\prime}= & \left\{\boldsymbol{X}_{1}, \boldsymbol{X}_{2}, \ldots, \boldsymbol{X}_{n+1}\right\}, \\
\text { s.t. } & \\
& \forall i \in \boldsymbol{I}^{\prime}, \forall x_{i} \in \boldsymbol{X}^{\prime}, f_{i}\left(\overline{\boldsymbol{x}} \| x_{i}\right)-f_{i}(\overline{\boldsymbol{x}}) \leq 0 \\
& \forall x_{n+1} \in \boldsymbol{X}_{n+1}, f_{n+1}\left(\overline{\boldsymbol{x}} \| x_{n+1}\right)-f_{n+1}(\overline{\boldsymbol{x}}) \leq 0 \\
& \overline{\boldsymbol{x}}=\left\{\bar{x}_{1}, \bar{x}_{2}, \ldots, \bar{x}_{n+1}\right\}, \boldsymbol{X}_{n+1}=\boldsymbol{Y}, \bar{x}_{n+1}=\bar{y}
\end{array}
$$

where the strategy of the "disturber" $x_{n+1}$ is the uncertain variable $y$, and its profit is the opposite value of other players.

There is no need to traverse uncertain parameters in the game expressed in Equation (11); thus, it can be easily solved. The uncertain output characteristics of distributed PV can be characterized by a virtual player, and the game theory method can be used to analyze the integrated energy transaction process with the influence of uncertain factors. The "disturber" represents the decision making for uncertain variables by the entity decision maker. Therefore, the decision-making behavior of the "disturber" in the game process is a reflection of the entity's self-interest in the game process. The decision space of the 
"disturber" is the fluctuation range of the uncertain variable, and its decision value is any possible value of the uncertain variable, as shown in Figure 1.

multi strategy evolutionary game

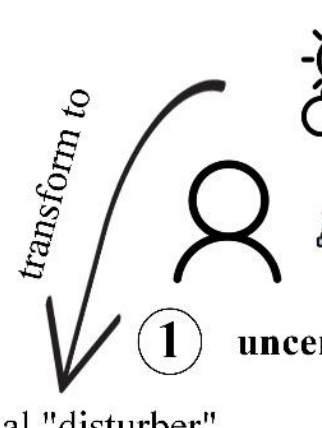

virtual "disturber"

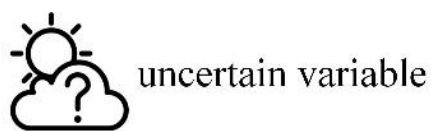

욜요

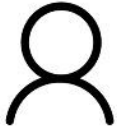

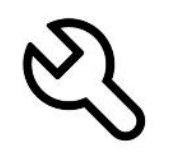
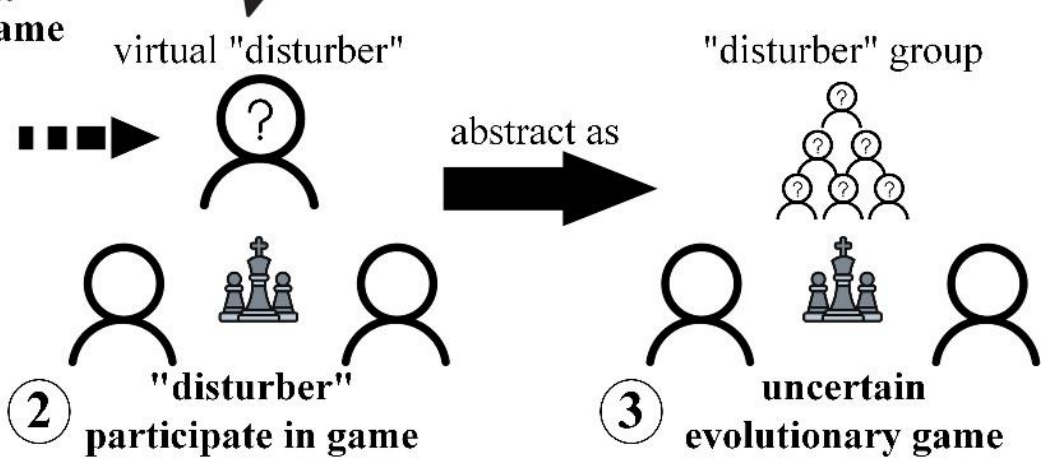

"disturber" group

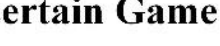

Figure 1. Diagram of uncertain evolutionary game.

When the fluctuation range of the uncertain variable is not clear, and the probability distribution of the value is not uniform, the "disturber" is equivalent to a player with bounded rationality. The game process can be regarded as an incomplete information game. This paper applies the evolutionary game method to solve this problem. The evolutionary game method combines traditional game thinking and evolutionary analysis theory to study the dynamic game process of game participants under the condition of incomplete rationality and incomplete information symmetry. The two core concepts of evolutionary game theory are the evolutionary stable strategy (ESS) and copying dynamic equations, which can characterize game stability points and dynamic convergence processes. Considering that the renewable energy output in an RIES fluctuates randomly within a certain interval, the multi-strategy evolutionary game method is adopted to deal with the uncertain evolutionary game in this paper [28].

\subsection{Characteristic Model of Distributed Photovoltaic Output}

A PV installation can reach about $100-200 \mathrm{~kW}$ in a CIES, and the impact of its volatility on system operation cannot be underestimated. Therefore, it is necessary to consider the uncertainty of PV output in the process of regional energy transactions to optimize the consumption plans of each energy-consuming entity in CIES, minimize system energy loss, and reduce the impact of PV output fluctuations.

Under standard test conditions, when the solar radiation intensity reaches $1000 \mathrm{~W} / \mathrm{m}^{2}$ and the temperature is $25^{\circ} \mathrm{C}$, according to the rated output of the PV panel, the actual PV output correction formula is expressed as

$$
p_{\mathrm{PV}}=p_{\mathrm{vst}} \frac{K_{\mathrm{ING}}}{K_{\mathrm{vst}}}\left[1+k_{\mathrm{PV}}\left(T_{\mathrm{c}}-T_{\mathrm{r}}\right)\right],
$$

where $K_{\mathrm{ING}}$ is the sunshine intensity of the operating environment, $K_{\mathrm{vst}}$ is the standard condition sunshine intensity, $k_{\mathrm{PV}}$ is the unit temperature power coefficient, and $T_{\mathrm{C}}$ and $T$ are the battery and the environmental temperature, respectively.

The output of PV panels is determined by the intensity of sunlight and the temperature difference between the battery and the environment. Therefore, when the weather condi- 
tions change, the intensity of sunlight fluctuates, or the ambient temperature is abnormal, the output of PV panels will vary within a certain range. This paper describes the PV output at time $t$ during the operation of the system in a CIES as a unit.

$$
\begin{aligned}
& p_{\mathrm{PV} i}^{t}=\bar{p}_{\mathrm{PV} i}^{t}+\hat{p}_{\mathrm{PV} i}^{t} \\
& \hat{p}_{\mathrm{PV} i}^{t} \in\left[\hat{p}_{\mathrm{PV} i, \mathrm{~min}^{\prime}}^{t} \hat{p}_{\mathrm{PV} i, \mathrm{max}}^{t}\right]^{\prime}
\end{aligned}
$$

where $p_{\mathrm{PV} i}^{t}$ is the preset value of PV output at time $t, \hat{p}_{\mathrm{PV} i}^{t}$ is the fluctuation deviation at time $t$, and $\hat{p}_{\mathrm{PV} i \text {,min }}^{t}$ and $\hat{p}_{\mathrm{PV} i \text {,max }}^{t}$ are the lower limit and upper limit of the fluctuation deviation, respectively.

The discrete probability distribution can effectively fit the PV output under different meteorological conditions. The beta distribution is used to describe the probability distribution for the deviation of PV output fluctuation [29].

$$
\begin{aligned}
& f\left(p_{\mathrm{PV}}^{t}\right)=\frac{\Gamma(\alpha+\beta)}{\Gamma(\alpha) \Gamma(\beta)}\left(\frac{p_{\mathrm{PV}}^{t}}{p_{\mathrm{PV}, \mathrm{max}}^{t}}\right)^{\alpha-1}\left(1-\frac{p_{\mathrm{PV}}^{t}}{p_{\mathrm{PV}, \mathrm{max}}^{t}}\right)^{\beta-1} \\
& \left\{\begin{array}{c}
\hat{f}\left(\hat{p}_{\mathrm{PV} i}^{t}\right)=\frac{f\left(\bar{p}_{\mathrm{PV} i}^{t}+\hat{p}_{\mathrm{PV} i}^{t}\right)}{\int_{p_{\mathrm{PV} i, \min }^{t} f\left(p_{\mathrm{PV}}^{t}\right) \mathrm{d} x}^{t}} \\
p_{\mathrm{PV} i, \max }^{t}=\bar{p}_{\mathrm{PV} i}^{t}+\hat{p}_{\mathrm{PV} i, \max }^{t} \\
p_{\mathrm{PV} i, \min }^{t}=\bar{p}_{\mathrm{PV} i}^{t}+\hat{p}_{\mathrm{PV} i, \min }^{t}
\end{array}\right.
\end{aligned}
$$

where $\alpha$ and $\beta$ are the beta distribution shape parameters.

Thus, from the perspective of the PV operator, combined with the probability and impact of the fluctuation value, the most stable output fluctuation estimated value can be obtained using the uncertain evolutionary game method described in Section 3.1, thereby optimizing the production capacity and trading plan.

The PV output device is set as the "disturber" in the virtual game. The game object of the "disturber" is to maximize its profit, which is the opposite of the operator's profit, and the strategy set is the fluctuation interval. The evolutionary game model can be described as

$$
\begin{aligned}
& \mathrm{DG}=\{\boldsymbol{P}, \boldsymbol{D}, \boldsymbol{U}(\boldsymbol{d})\} \\
& \left\{\begin{array}{l}
\boldsymbol{D}=\left\{d_{1}, d_{2}, \ldots d_{i} \ldots d_{n}\right\} \\
\hat{p}_{\mathrm{PV} i, \min }^{t} \leq d_{i} \leq \hat{p}_{\mathrm{PV} i, \max }^{t} \\
P\left(d_{i}=\hat{p}_{\mathrm{PV} i}^{t}\right)=\hat{f}\left(\hat{p}_{\mathrm{PV} i}^{t}\right) \cdot \Delta x
\end{array}\right.
\end{aligned}
$$

where $\boldsymbol{P}$ is the abstract set of "disturbers", $\boldsymbol{D}$ is the volatility deviation strategy set, $\boldsymbol{U}(\boldsymbol{d})$ is the profit function of the "disturbers", $d_{i}$ is the strategy value ranging within the fluctuation deviation interval, and $P\left(d_{i}=\hat{p}_{\mathrm{PV} i}^{t}\right)$ is the occurrence probability, which is multiplied by the differential step length $\Delta x$ and the fluctuation probability density $\hat{f}\left(\hat{p}_{\mathrm{PV} i}^{t}\right)$.

The profit function is described as

$$
\left\{\begin{array}{l}
\boldsymbol{u}(\boldsymbol{d})=-E_{\mathrm{m} i}^{t} \\
E_{\mathrm{m} i}^{t}=E_{\mathrm{om} i}^{t}+E_{\mathrm{mu} i}^{t}-F_{i}^{t}
\end{array} .\right.
$$

The profit of each CIESs consists of the transaction profit, energy utility, and gas purchase cost. Operators optimize the profit objective function by optimizing production capacity and purchasing and selling energy plans. 


$$
\begin{aligned}
& \max E_{\mathrm{m} i}^{t}\left(p_{\mathrm{chp} i}^{t}, P_{\mathrm{ms} i}^{t}, P_{\mathrm{mh} i}^{t}, A_{\mathrm{e} i}^{t}, B_{\mathrm{h} i}^{t}\right) \\
& \text { s.t. } \\
& p_{\mathrm{u} i}^{t}-p_{\mathrm{chp} i}^{t}-\bar{p}_{\mathrm{PV} i}^{t}-\hat{p}_{\mathrm{PV} i}^{t}=p_{\mathrm{eg} i}^{t}-l p_{\mathrm{g} i}^{t}+\sum_{j=1}^{G}\left(p_{\mathrm{e} j i}^{t}-l p_{j, i}^{t}\right), \\
& \quad l h_{i}^{t}-v_{\mathrm{he}} p_{\mathrm{chp} i}^{t}=\sum_{j=1}^{G}\left(l_{\mathrm{h} j i}^{t-\Delta t}-h_{\mathrm{loss} j, i}^{t}\right) \\
& a_{j, 1}^{i, t}=p_{\mathrm{e} i j}^{t}, b_{j, 1}^{i, t}=l_{\mathrm{h} i j}^{t},
\end{aligned}
$$

where $A_{\mathrm{e} i}^{t}$ and $\boldsymbol{B}_{\mathrm{h} i}^{t}$ are the optimal purchase and sale plan matrices of electricity and heat according to the preset value of PV output when the $i$-th operator does not consider PV fluctuations, while $a_{j, 1}^{i, t}$ and $b_{j, 1}^{i, t}$ are the elements in the $j$-th row and the first column of the matrix $A_{\mathrm{e} i}^{t}$ and $\boldsymbol{B}_{\mathrm{h} i}^{t}$, respectively.

Within the power balance constraints, after the PV output fluctuates, to meet local consumption, the operator needs to produce energy through the CHP unit or purchase the balance of electricity from the power grid immediately. This process increases the cost of purchasing energy, thus reducing the profit. Therefore, the "disturber" can adopt different volatility value strategies $\boldsymbol{d}_{i}$ to obtain the corresponding profit function $\boldsymbol{U}\left(\boldsymbol{d}_{i}\right)$ and obtain the evolutionary stable strategy ESS through the proposed multi-strategy evolutionary game.

\section{Optimal Operation Strategy for Regional Integrated Energy System}

\subsection{Regional Integrated Energy System Structure}

An RIES is composed of multiple CIESs, as well as electricity, heat, gas and communication grids. A $10 \mathrm{kV}$ medium-voltage DN is usually used as the physical framework for an RIES. The system includes distributed PV, CHP, power to gas (P2G), and other energy sources. The load capacity is 5-10 MW. Its energy flow structure is shown in Figure 2.
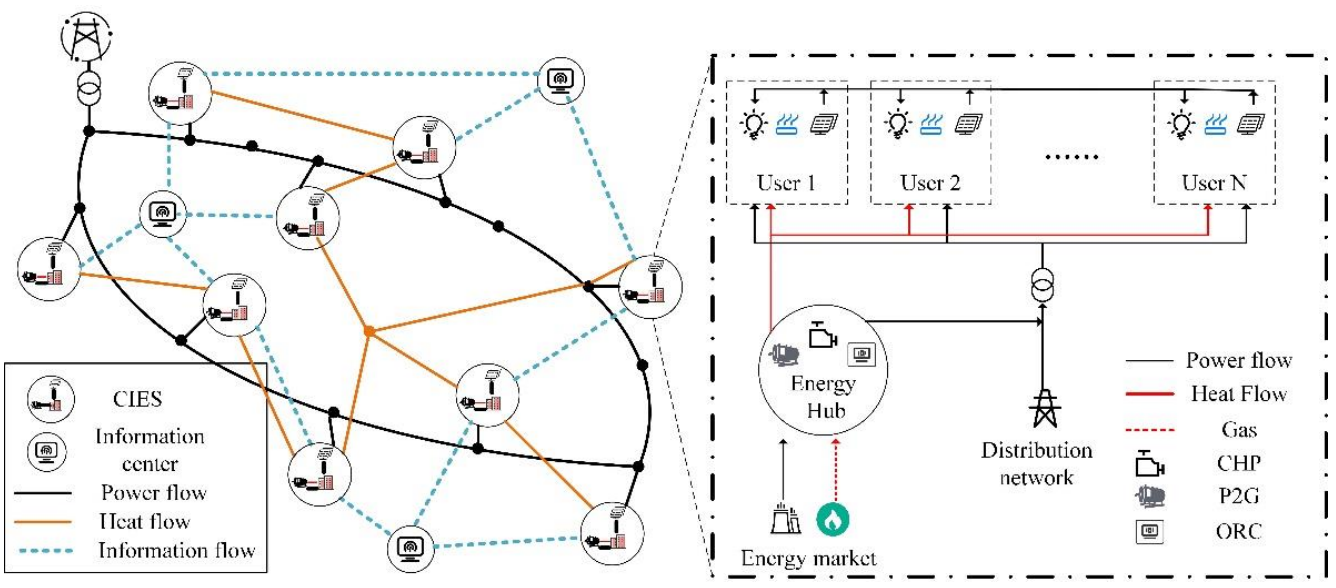

Figure 2. Diagram for energy flow of an RIES.

The main participants in energy transactions are the energy operator, grid companies, and users of electricity and heat. The production plans and trading strategies are formulated by the operator. The electricity and gas are purchased from the energy market and converted into electricity and heat. The power grid participates in market transactions, which can provide users with stable power and form a competitive relationship with the operator; users can meet the load demand through transactions with the operator or power grids. At the same time, users can adjust their energy consumption at various timepoints to share surplus PV output or complete transactions.

The RIES operator can use CHP to produce electricity and heat to meet the needs of local users, and they can also sell surplus energy to other community operators and users 
for profit. Users can consume local wind, PV, and other renewable energy, or purchase electricity and heat from the community operator and power grid. The grid company provides stable power load to users in the $\mathrm{DN}$, and it is responsible for absorbing the surplus output in the region or filling the power gap. All participating entities are connected to the information flow through communication lines to realize the sharing of energy use information between operator and users, as well as coordinate energy dispatch in the area. The operator uses the information platform to communicate the capacity and load levels of each community; they can formulate their own optimal capacity plans and trading strategies on the basis of the local load demand and external energy flow conditions, as well as eliminate redundant capacity and improve regional energy use efficiency.

\subsection{Energy-Consumption and Profit Models}

\subsubsection{Energy-Consumption Model}

User load includes electrical load and thermal load. The electrical load can be adjusted in each time period, but it must meet the energy-consumption constraints of each time period and meet the total energy consumption of the day. The thermal load is capable of meeting the heating and cooling needs of users in each time period, and the energyconsumption situation is relatively stable.

The user's electrical load includes fixed load, shiftable load, and PV power output. The fixed load has higher requirements for power supply reliability, and its energy-consumption period is relatively fixed. The shiftable load requires that the total energy consumption of the day meets the demand, and its period can be adjusted. The PV power output is consumed by user load; if there is surplus power, it can be sold to the power grid or operator. The net power load of user $i$ in the $t$-th period is expressed as

$$
p_{i}^{t}=l s_{i}^{t}+l f_{i}^{t}-p l_{i}^{t}
$$

where $l s_{i}^{t}$ and $l f_{i}^{t}$ are the translational load and fixed load of user $i$ during the $t$-th period, respectively, and $p l_{i}^{t}$ is the active power output of the PV power of user $i$ during the $t$-th period.

The shiftable load is arranged by user according to the electricity price and PV output in each period. The initial shiftable load of user $i$ in each period can be expressed as

$$
\begin{aligned}
& {\left[l s_{i}^{1 *}, l s_{i}^{2 *}, \ldots, l s_{i}^{t *}, \ldots, l s_{i}^{H *}\right]=L S_{i} \cdot\left[u_{i}^{1}, u_{i}^{2}, \ldots, u_{i}^{t}, \ldots, u_{i}^{H}\right]} \\
& \sum_{t=1}^{H} u_{i}^{t}=1, u_{i \min }^{t} \leq u_{i}^{t} \leq u_{i \max }^{t}
\end{aligned}
$$

where $l s_{i}^{t *}$ is the initial translational load of user $i$ during the $t$-th period, $L S_{i}$ is the total shiftable load of user $i$ in 1 day, and $u_{i}^{t}$ is the period allocation coefficient for the shiftable load of user $i$ during the $t$-th period.

\subsubsection{Profit Model}

User profit is divided into energy utility and transaction profit. Energy utility is the value produced by users using electricity and thermal load, and it is characterized by economic benefits. Transaction profit is earned by users who buy energy from suppliers or sell PV power. The user adjusts the load demand in each time period according to the purchase and sale price of electricity and PV power output, in order to maximize their own profit. The profit of user $i$ is expressed as

$$
\left\{\begin{array}{l}
E U_{i}=\sum_{t=1}^{H} E U_{i}^{t} \\
E U_{i}^{t}=E P_{i}^{t}+E T_{i}^{t}
\end{array},\right.
$$

where $E U_{i}^{t}$ is the profit of user $i$ during the $t$-th period, which is composed of energy utility $E P_{i}^{t}$ and transaction profit $E T_{i}^{t}$. 
User load adjustment and economic benefits are considered to be linearly related in this paper, which can be expressed as

$$
\begin{aligned}
E P_{i}^{t} & =\alpha_{i}\left(p_{i}^{t}+l h_{i}^{t}\right)+\delta_{i} \\
E T_{i}^{t} & =P_{\mathrm{CEI}}^{t}\left(-P_{\mathrm{ms}}^{t} \frac{\left|p_{i}^{t}\right|+p_{i}^{t}}{2}+P_{\mathrm{mb}}^{t} \frac{\left|p_{i}^{t}\right|-p_{i}^{t}}{2}\right) \\
& +P_{\mathrm{G}}^{t}\left(-P_{\mathrm{gs}}^{t} \frac{\left|p_{i}^{t}\right|+p_{i}^{t}}{2}+P_{\mathrm{gb}}^{t} \frac{\left|p_{i}^{t}\right|-p_{i}^{t}}{2}\right)-P_{\mathrm{mh}}^{t} l h_{i}^{t} \\
P_{\mathrm{CEI}}^{t} & +P_{\mathrm{G}}^{t}=1
\end{aligned}
$$

where $\alpha_{i}$ and $\delta_{i}$ are the utility parameters of user $i$, and $P_{\mathrm{G}}^{t}$ is the probability of user completing a transaction with the power grid.

\subsection{Energy Flow and Profit Model}

\subsubsection{Energy Flow Model}

There is an energy connection mechanism between CIESs, which can mutually absorb or supplement the residual electricity or heat produced by the CHP unit, so as to realize the efficient use of energy. Its production system is mainly composed of CHP and distributed PV, which use microturbines (MTs) to simultaneously produce electric and thermal energy by inputting gas. Due to the thermoelectric coupling characteristics of the unit, CHP usually operates in "following electrical load (FEL)" or "following thermal load (FTL)" modes.

In the FEL operation mode, the difference between the CHP heat production and the thermal load demand needs to be supplemented through the external energy system. If the difference is positive, the surplus thermal energy is sold to the outside; if the difference is negative, the supplementary thermal energy is purchased from the outside. The thermal energy difference can be calculated as

$$
\begin{aligned}
& \Delta H_{\text {fel } i}^{t}=v_{\text {he }} p_{i}^{t}-l h_{i}^{t} \\
& v_{\text {he }}=\left(1-\eta_{\mathrm{e}}-\eta_{\text {loss }}\right) \eta_{\mathrm{h}} / \eta_{\mathrm{e}}
\end{aligned},
$$

where $p_{i}^{t}$ is the electrical load of user $i$ in time period $t, l h_{i}^{t}$ is the thermal load of user $i$ in time period $t$, and $v_{\text {he }}$ is the CHP thermoelectric ratio coefficient.

In the FTL operation mode, the electrical energy difference can be calculated as

$$
\Delta P_{\mathrm{ftl} i}^{t}=v_{\mathrm{he}}^{-1} l h_{i}^{t}-p_{i}^{t} .
$$

Since the CIESs operate jointly, the CHP can flexibly select operating conditions to make up for the lack of electric heating load or sell surplus capacity through transactions with other CIESs or the power grid. The operator can interconnect with other CIESs on the basis of local load levels, combined with external energy prices, and adjust their own operating methods and operating conditions to increase local profit. The user load in a single CIES cannot be completely matched with the energy produced by the CHP unit according to the fixed heat-to-power ratio. Thus, each CIES needs to coordinate operation to complement the differential load.

Each CIES generates energy flow through transactions, and this energy flow needs to meet the power balance and network loss constraints. The mixed energy flow in an RIES is composed of an electrical component and a thermal component. The electrical energy component is generated through electrical energy transactions between CIESs or between a CIES and the power grid. The purchased electricity of each CIES must meet the power balance conditions.

$$
\begin{aligned}
& \Delta p_{i}^{t}=p_{\mathrm{eg} i}^{t}-l p_{\mathrm{g} i}^{t}+\sum_{j=1}^{G}\left(p_{\mathrm{e} j i}^{t}-l p_{j, i}^{t}\right) \\
& l p_{i, j}^{t}=\frac{\left(p_{\mathrm{e} i j}^{t}\right)^{2}}{U^{2}} R_{i j}
\end{aligned}
$$


where $\Delta p_{i}^{t}$ is the imbalance power, $l p_{\mathrm{g} i}^{t}$ is the power loss generated in the DN when the power is transmitted from user $j$ to user $i, U$ is the DN line voltage, $R_{i j}$ is the line resistance, and $l p_{\mathrm{g} i}^{t}$ is the power loss from power grid node to user $i$.

Due to the existence of a certain length of heating network pipelines, and the slow mass flow rate of the heating medium in the heating network, the time delay effect needs to be considered when formulating thermal energy purchase and sale plans. The thermal energy balance conditions are as follows:

$$
\left\{\begin{array}{l}
\Delta H_{i}^{t}=\sum_{j=1}^{G}\left(l_{\mathrm{h} j i}^{t-\Delta t}-h_{\mathrm{loss} j, i}^{t}\right) \\
h_{\mathrm{loss} i, j}^{t}=c^{H} m^{W}\left(T_{j}^{t-\Delta t}-T_{i}^{t}\right) \\
T_{i}^{t}=\left(T_{j}^{t-\Delta t}-T_{\mathrm{s}}\right) \exp \left(-\frac{\zeta L_{i, j}}{c^{H} m^{W}}\right)+T_{\mathrm{s}}
\end{array},\right.
$$

where $\Delta H_{i}^{t}$ is the thermal energy difference of user $i$ in time period $t, \Delta t$ is the thermal energy transmission time delay, $h_{\text {loss } j, i}^{t}$ is the thermal energy network loss, $c^{H}$ and $m^{W}$ are the heat medium specific heat capacity and the heat medium mass flow rate, respectively, $T_{j}^{t-\Delta t}$ is the temperature of the heat medium output from user $i$ in time period $t, T_{i}^{t}$ is the temperature of the heat medium input to user $i$ in time period $t, T_{\mathrm{S}}$ is the ambient temperature of the heating network pipe, $\zeta$ is the heat transfer coefficient of the heating network pipe, and $L_{i, j}$ is the length of the pipe space from user $i$ to user $j$.

Considering that all parameters, except for $T_{j}^{t-\Delta t}$ and $T_{i}^{t}$, are known constants, Equation (26) can be simplified to

$$
\left\{\begin{array}{l}
h_{\mathrm{loss} i, j}^{t}=\lambda_{i, j} \mathrm{~h}_{\mathrm{h} i j}^{t-\Delta t}-C_{\mathrm{s}}^{i, j} \\
\lambda_{i, j}=1-\exp \left(-\frac{\zeta L_{i, j}}{c^{H} m^{W}}\right) . \\
C_{\mathrm{s}}^{i, j}=\lambda_{i, j} c^{H} m^{W} T_{\mathrm{s}}
\end{array}\right.
$$

\subsubsection{Profit Model}

Each CIES operator can simultaneously act as an energy seller and buyer. They can trade electricity and thermal energy with other CIESs through the DN or heat supply network, with the ability to respond to heat and electricity demand, and they can adjust a certain proportion of local load. User profit consists of energy sales profit, energy efficiency, and gas purchase cost.

$$
\begin{aligned}
& E_{\mathrm{m} i}^{t}=E_{\mathrm{om} i}^{t}+E_{\mathrm{mu} i}^{t}-F_{i}^{t} \\
& \text { s.t. } \\
& \qquad \begin{array}{l}
E_{\mathrm{om} i}^{t}=E_{\mathrm{mg} i}^{t}+\sum_{j=1}^{G}\left(E_{\mathrm{me} i j}^{t}+E_{\mathrm{mh} i j}^{t}\right) \\
E_{\mathrm{mu} i}^{t}=E P_{i}^{t}+E H_{i}^{t} \\
E_{\mathrm{mg} i}^{t}=P_{\mathrm{gb}}^{t}\left(\frac{\left|p_{\mathrm{eg} i}^{t}\right|+p_{\mathrm{e} i}^{t}}{2}\right)-P_{\mathrm{gs}}^{t}\left(\frac{\left|p_{\mathrm{eg} i}^{t}\right|-p_{\mathrm{eg} i}^{t}}{2}\right), \\
E_{\mathrm{me} i j}^{t}=P_{\mathrm{ms} i}^{t}\left(\frac{\left|p_{\mathrm{e} i j}^{t}\right|+P_{\mathrm{e} i j}^{t}}{2}\right)-P_{\mathrm{ms} j}^{t}\left(\frac{\left|p_{\mathrm{e} i j}^{t}\right|-p_{\mathrm{e} i j}^{t}}{2}\right) \\
E_{\mathrm{mh} i j}^{t}=P_{\mathrm{mh} i}^{t}\left(\frac{\left|l_{\mathrm{h} i j}^{t}\right|+l_{\mathrm{h} i j}^{t}}{2}\right)-P_{\mathrm{mh} j}^{t}\left(\frac{\left|l_{\mathrm{h} i j}^{t}\right|-l_{\mathrm{h} i j}^{t}}{2}\right)
\end{array}
\end{aligned}
$$

where $E_{\mathrm{mg} i}^{t}$ is the profit from electrical energy exchange with the power grid, $p_{\mathrm{e} g}^{t}$ is the electrical energy sold to the power grid (a negative value denotes a purchase of electrical 
energy from the power grid), $E_{\text {meij }}^{t}$ is the electrical energy transaction profit between user $i$ and $j, P_{\mathrm{ms} i}^{t}$ and $P_{\mathrm{ms} j}^{t}$ are the selling prices, $E_{\mathrm{mh} i j}^{t}$ is the thermal energy transaction profit between CIESs, $P_{\mathrm{mh} i}^{t}$ and $P_{\mathrm{mh} j}^{t}$ are the heat selling prices, $p_{\mathrm{e} i j}^{t}$ and $l_{\mathrm{h} i j}^{t}$ are the electricity and thermal energy sold by user $i$ to $j$ (a negative value denotes that user $i$ purchases electricity or thermal energy from user $j$ ), and $G$ is the total number of CIESs in the RIES.

The energy efficiency $E_{\mathrm{mu} i}^{t}$ is a function of the user's electricity and heat consumption, in which the electricity utility $E P_{i}^{t}$ and heat utility $E H_{i}^{t}$ are calculated as follows:

$$
\begin{aligned}
& E P_{i}^{t}=a_{i} p_{i}^{t}+b_{i} \leq E P_{\max _{i} i}^{t} \\
& E H_{i}^{t}=\left\{\begin{array}{c}
\alpha_{i} l h_{i}^{t}-\delta_{i}\left(l h_{i}^{t}\right)^{2}, l h_{i}^{t} \leq \frac{\alpha_{i}}{2 \delta_{i}} \quad, \\
\frac{\alpha_{i}{ }^{2}}{4 \delta_{i}}, l h_{i}^{t}>\frac{\alpha_{i}}{2 \delta_{i}}
\end{array}\right.
\end{aligned}
$$

where $a_{i}$ and $b_{i}$ are power efficiency parameters, $E P_{i}^{t}$ is within the utility limit value $E P_{\max , i}^{t}$ and $\alpha_{i}$ and $\delta_{i}$ are the thermal adjustment parameter coefficients.

The gas purchase cost $F_{i}^{t}$ consists of the fuel cost of the CHP unit, which is calculated as

$$
F_{i}^{t}=P_{\mathrm{h}}^{t} \frac{p_{\mathrm{chp} i}^{t}}{\eta_{\mathrm{e} i} \mathrm{H}_{\mathrm{hvn}}},
$$

where $P_{\mathrm{h}}^{t}$ is the unit price of gas, $p_{\text {chpi }}^{t}$ is the power generation output, $\mathrm{H}_{\mathrm{hvn}}$ is the low calorific value of gas, and $\eta_{\mathrm{e} i}$ is the power generation efficiency of the CHP unit.

\subsection{Energy System and Operator Profit Models}

\subsubsection{Energy System Model}

The energy system model with a multi-energy conversion function is constructed according to the idea of an energy hub (EH), which is composed of P2G, CHP, and an organic Rankine cycle waste heat power generation system (ORCPG). The operator can flexibly adjust the input, output, and conversion ratio of each energy type to meet the load demand and reduce the energy purchase cost.

\section{(1) Power-to-gas equipment}

P2G is a key link for EH to realize the conversion of electricity to gas. Its action mechanism is to use electrical energy to convert water or carbon dioxide into hydrogen or methane. Generally, the conversion product needs to be coupled and matched with the gas heating system. Hydrogen is not easy to store in the gas system; hence, methane is taken as the final product in this paper. The production of methane by P2G mainly goes through two main chemical processes. Firstly, sufficient hydrogen is obtained by electrolyzing water, and oxygen is released. Then, hydrogen is reacted with carbon dioxide under the action of a catalyst in a high-temperature and high-pressure environment to obtain methane and water. Except for the main product methane, no pollutants are generated in the preparation process. Water resources are recycled while consuming greenhouse gas carbon dioxide, which is a clean and green production mode of converting electricity to gas.

(2) Combined heat and power unit

$\mathrm{CHP}$ is the main physical equipment for the operator to convert gas to electricity. The back-pressure thermoelectric unit is generally adopted in a CIES, which is suitable for small-scale power generation scenarios, and it is generally used in environments with a load capacity of less than $20 \mathrm{MW}$. The CHP simultaneously produces electricity and thermal energy in the same proportion; during separate operation, the back-pressure CHP operates in FEL or FTL modes.

(3) Waste heat power generation system

ORCPG uses the organic Rankine cycle mechanism to realize the function of lowtemperature power generation from waste heat. By operating in conjunction with the $\mathrm{CHP}$ 
unit, it can achieve the high-efficiency conversion of waste heat, as well as the effect of thermoelectric decoupling. The system functions through preheating, evaporating, and condensing the working fluid (pentafluoropropane) to drive the steam turbine for the conversion of thermal to electrical energy. As a new method of clean power generation, it will occupy an important position in the future development of the low-carbon economy energy market. The operator can use the ORCPG to convert the waste heat generated by CHP into electrical energy, which can improve the power generation efficiency of the cogeneration system and increase the conversion range of thermal power.

\section{(4) Energy hub model}

Through the joint operation of CHP with P2G and ORCPG, the residual electricity or waste heat is converted by the coupling equipment in the $\mathrm{EH}$ system, which can address the limitation of inherent FEL and FTL modes, strengthen the flexibility of energy conversion, improve energy efficiency, and reduce energy purchase costs. The energy flow in an EH system is shown in Figure 3.

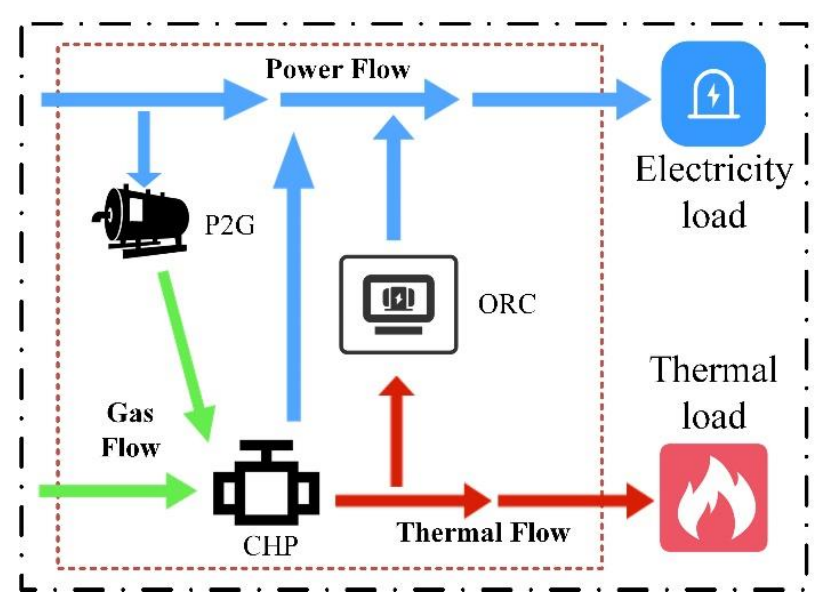

Figure 3. Diagram of energy flow in EH.

The inputs are electricity and gas, while the outputs are electricity and thermal flow to users. In terms of power flow, electrical energy can be directly provided to users for electrical demand or can be obtained through gas produced by $\mathrm{P} 2 \mathrm{G}$ and transported to $\mathrm{CHP}$ to be converted into thermal and electrical energy for users. As for gas flow, gas is burned in CHP to produce electrical energy and thermal energy; the former can be directly supplied to users, while the latter can be used to meet the thermal load or further produce electrical energy through the ORCPG.

According to the EH framework, the operator can use electricity and gas purchased from the energy market as input energy to output electricity and heat on the basis of the demand. The operation mechanism of each equipment can be synthesized to obtain the energy flow equation of $\mathrm{EH}$ as follows:

$$
\left\{\begin{array}{l}
p_{\mathrm{be}}^{t}-p_{\mathrm{P} 2 \mathrm{G}}^{t}+\eta_{\mathrm{e}}\left(p_{\mathrm{bh}}^{t}+\eta_{\mathrm{P} 2 \mathrm{G}} p_{\mathrm{P} 2 \mathrm{G}}^{t}\right)+\eta_{\mathrm{orc}} p_{\mathrm{orc}}^{t}=p_{\mathrm{e}}^{t} \\
\left(p_{\mathrm{bh}}^{t}+\eta_{\mathrm{P} 2 \mathrm{G}} p_{\mathrm{P} 2 \mathrm{G}}^{t}\right) \cdot\left(1-\eta_{\mathrm{e}}-\eta_{\mathrm{loss}}\right) \cdot \eta_{\mathrm{h}}-p_{\mathrm{orc}}^{t}=p_{\mathrm{h}}^{t}
\end{array},\right.
$$

where $p_{\mathrm{e}}^{t}$ and $p_{\mathrm{h}}^{t}$ are the output electricity and thermal load during the $t$-th period, $p_{\mathrm{be}}^{t}$ and $p_{\mathrm{bh}}^{t}$ are the electrical energy and gas traded between the operator and energy market during the $t$-th period, respectively, $p_{\mathrm{P} 2 \mathrm{G}}^{t}$ is the electrical energy delivered to P2G for conversion during the $t$-th period, $\eta_{\mathrm{P} 2 \mathrm{G}}$ is the conversion efficiency of $\mathrm{P} 2 \mathrm{G}, p_{\mathrm{orc}}^{t}$ is the thermal energy delivered to the ORCPG for power generation during the $t$-th period, and $\eta_{\text {orc }}$ is the power generation efficiency of the ORCPG. 
Equation (31) can be rewritten as

$$
\left\{\begin{array}{c}
\eta_{\mathrm{P} 2 \mathrm{G}} \cdot\left(1-\eta_{\mathrm{e}}-\eta_{\text {loss }}\right) \cdot \eta_{\mathrm{h}} \frac{p_{\mathrm{P} 2 \mathrm{G}}^{t}}{p_{\mathrm{be}}^{t}} p_{\mathrm{be}}^{t} \\
+\left[\left(1-\eta_{\mathrm{e}}-\eta_{\text {loss }}\right) \cdot \eta_{\mathrm{h}}-\frac{p_{\mathrm{orc}}^{t}}{p_{\mathrm{bh}}^{t}}\right] \cdot p_{\mathrm{bh}}^{t}=p_{\mathrm{h}}^{t} \\
{\left[1+\left(\eta_{\mathrm{P} 2 \mathrm{G}} \eta_{\mathrm{e}}-1\right) \frac{p_{\mathrm{P} 2 \mathrm{G}}^{t}}{p_{\mathrm{be}}^{t}}\right] \cdot p_{\mathrm{be}}^{t}} \\
+\left(\eta_{\mathrm{e}}+\eta_{\mathrm{orc}} \cdot \frac{p_{\mathrm{orc}}^{t}}{p_{\mathrm{bh}}^{t}}\right) \cdot p_{\mathrm{bh}}^{t}=p_{\mathrm{e}}^{t}
\end{array} .\right.
$$

Let

$$
\left\{\begin{array}{l}
\beta=p_{\mathrm{P} 2 \mathrm{G}}^{t} / p_{\mathrm{be}}^{t} \\
\theta=p_{\mathrm{orc}}^{t} / p_{\mathrm{bh}}^{t} \\
\eta_{\mathrm{hh}}=\left(1-\eta_{\mathrm{e}}-\eta_{\mathrm{loss}}\right) \cdot \eta_{\mathrm{h}} \\
\eta_{\mathrm{eh}}=\eta_{\mathrm{P} 2 \mathrm{G}} \cdot\left(1-\eta_{\mathrm{e}}-\eta_{\mathrm{loss}}\right) \cdot \eta_{\mathrm{h}}
\end{array} .\right.
$$

Then, Equation (32) can be simplified as

$$
\left[\begin{array}{c}
p_{\mathrm{e}}^{t} \\
p_{\mathrm{h}}^{t}
\end{array}\right]=\left[\begin{array}{cc}
1+\left(\eta_{\mathrm{P} 2 \mathrm{G}} \eta_{\mathrm{e}}-1\right) \beta & \eta_{\mathrm{e}}+\eta_{\mathrm{orc}} \theta \\
\eta_{\mathrm{eh}} \beta & \eta_{\mathrm{hh}}-\theta
\end{array}\right] \cdot\left[\begin{array}{c}
p_{\mathrm{be}}^{t} \\
p_{\mathrm{bh}}^{t}
\end{array}\right],
$$

where $\beta$ and $\theta$ are the dispatch factors of electricity and thermal energy input to P2G and the ORCPG, $\eta_{\mathrm{eh}}$ is the conversion efficiency electricity passing through P2G and CHP into thermal energy, $\eta_{\mathrm{hh}}$ is the conversion efficiency of gas into thermal energy through $\mathrm{CHP}$, and $p_{\mathrm{be}}^{t}$ and $p_{\mathrm{bh}}^{t}$ are the input of the EH system, while $p_{\mathrm{e}}^{t}$ and $p_{\mathrm{h}}^{t}$ are the output.

While meeting the electrical and thermal demand, the operator can optimize the DF value to adjust the input of P2G and ORCPG to reduce the external energy input and energy purchase costs, which can further improve the energy efficiency and operation profit.

\subsubsection{Operator Profit Model}

\section{(1) Profit model}

Operators obtain profit by selling electricity and thermal energy to users, while they can also recover the surplus output of PV and sell it to users. In the energy transaction market, the power grid participates in transactions as the entity that can provide highquality and stable electrical energy. Therefore, the operator needs to adjust the purchase and sale price of energy to compete with the power grid, thereby attracting users to purchase electricity at a preferential price. The profit is expressed as

$$
\left\{\begin{array}{l}
E_{\mathrm{m}}=\sum_{t=1}^{H} E_{\mathrm{m}}^{t} \\
E_{\mathrm{m}}^{t}=E G_{\mathrm{m}}^{t}+\sum_{i=1}^{G}\left(E E_{i}^{t}+E H_{i}^{t}\right)
\end{array},\right.
$$

where $G$ is the total number of users, and $E_{\mathrm{m}}^{t}$ is the profit during the $t$-th period, which is mainly composed of electricity sale profit $E E_{i}^{t}$, feeder profit $E G_{\mathrm{m}}^{t}$, and heat sale profit $E H_{i}^{t}$.

In Equation (35), electricity sale profit $E E_{i}^{t}$ is the income generated by purchasing and selling electric energy to/from user $i$, i.e.,

$$
\left\{\begin{array}{l}
E E_{i}^{t}=P_{\mathrm{CEI}}^{t}\left(P_{\mathrm{ms}}^{t} \frac{\left|p_{i}^{t}\right|+p_{i}^{t}}{2}-P_{\mathrm{mb}}^{t} \frac{\left|p_{i}^{t}\right|-p_{i}^{t}}{2}\right) \\
P_{\mathrm{CEI}}^{t}=a\left(1-\frac{P_{\mathrm{ms}}^{t}-P_{\mathrm{mb}}^{t}}{P_{\mathrm{gs}}^{t}-P_{\mathrm{gb}}^{t}}\right)+b
\end{array},\right.
$$

where $P_{\mathrm{ms}}^{t}$ is the electricity sale price of the operator during the $t$-th period, $P_{\mathrm{mb}}^{t}$ is the purchase price of surplus PV power from users during the $t$-th period, $p_{i}^{t}$ is the net load of user $i$ during the $t$-th period $\left(p_{i}^{t}>0\right.$ denotes that the user purchases from the operator or 
power grid to meet demand, while $p_{i}^{t}<0$ denotes that the user sells the surplus PV output to the operator or power grid), $P_{\mathrm{CEI}}^{t}$ is the probability that the user chooses the operator as the transaction object (the operator needs to compete with the power grid; hence, a lower electricity sale price $P_{\mathrm{ms}}^{t}$ or a higher electricity purchase price $P_{\mathrm{mb}}^{t}$ results in a greater probability of the operator successfully concluding a transaction with the user), $P_{\mathrm{gs}}^{t}$ and $P_{\mathrm{gb}}^{t}$ are the electricity sale price and purchase price of the power grid during the $t$-th period, and $a$ and $b$ are the adjustment coefficients.

Feeder profit $E G_{\mathrm{m}}^{t}$ refers to when the surplus electricity in the CIES cannot be absorbed locally, whereby the operator can feed this part of the electrical energy back to power grid to obtain a profit. This profit is generally generated when the thermal load is high and the demand for electricity load is extremely low.

$$
E G_{\mathrm{m}}^{t}=P_{\mathrm{gb}}^{t} \cdot \frac{\left|p_{\mathrm{be}}^{t}\right|-p_{\mathrm{be}}^{t}}{2}
$$

where $p_{\mathrm{be}}^{t}$ is the purchase demand obtained according to Equation (34). $p_{\mathrm{be}}^{t}>0$ denotes that there is no surplus power in this CIES during the $t$-th period, the feeder profit is zero, and the operator needs to purchase power from the outside. $p_{\mathrm{be}}^{t}<0$ denotes net surplus electricity during the $t$-th period, which can be recycled through the power grid to generate feeder profit.

Heat sale profit $E H_{i}^{t}$ is the profit generated by the operator selling thermal energy to user $i$, which can be calculated as

$$
E H_{i}^{t}=P_{\mathrm{mh}}^{t} l h_{i}^{t},
$$

where $P_{\mathrm{mh}}^{t}$ is the thermal energy sale price during the $t$-th period, and $l h_{i}^{t}$ is the thermal demand of user $i$ during the $t$-th period.

\section{(2) Cost model}

In energy transactions, the costs required by the operator are mainly energy purchase costs, including electricity purchase costs and gas purchase costs. With the operation and transaction methods of the energy market becoming more flexible, the electrical energy and gas required by the operator can be provided by electricity suppliers such as power plants and gas suppliers through the energy transaction market. The electricity purchase price $P_{\mathrm{e}}$ is calculated as a function of the marginal cost of power generation, and the gas purchase price $P_{\mathrm{h}}$ is fixed in the short term according to actual conditions. Therefore, the operator's energy purchase cost can be calculated as

$$
\left\{\begin{array}{l}
F=\sum_{t=1}^{H} F^{t} \\
F^{t}=\frac{\left|p_{\mathrm{be}}^{t}\right|+p_{\mathrm{be}}^{t}}{2} \cdot P_{\mathrm{e}}+\frac{p_{\mathrm{bh}}^{t}}{\mathrm{H}_{\mathrm{hvn}}} \cdot P_{\mathrm{h}} \\
P_{\mathrm{e}}=a_{1}+a_{2} \cdot p_{\mathrm{be}}^{t}
\end{array},\right.
$$

where $F^{t}$ is the energy purchase cost of the operator during the $t$-th period $\left(F^{t} \leq 0\right.$ denotes that the operator does not need to purchase electricity from the outside, and the cost of the electricity purchase part is zero, $H_{\mathrm{hvn}}$ is the low heating value of gas, and $a_{1}$ and $a_{2}$ are the marginal electricity price pricing parameters.

On the basis of the energy conversion characteristics of the $\mathrm{EH}$, the operator needs to optimize the dispatch factor to reduce energy purchase costs, as well as adjust energy sale prices to maximize profit while satisfying electrical and thermal demands.

\subsection{Optimal Operation Strategy}

\subsubsection{Energy Transaction Strategy of Community-Integrated Energy System}

A CIES is a specific component of an RIES; its internal transaction participants include the operator, power grid and users. The electricity purchase price and sale price of the 
power grid is fixed. The operator can adjust the purchase and sale price in each time period according to the load level. Users can adjust the shiftable load in each time period according to the electricity purchase and sale price. The operator and users are the main participants in energy transactions. The price set by the former affects the consumption of the latter, while the consumption of the latter affects the price of the former; the two parties play a game with each other to optimize their own profits. Therefore, we can establish a master-slave game model in which the operator is the master and plays with users, whereas users are the slaves and play with each other. After the individual users obtain a pricing strategy for purchasing and selling electricity, they compete to optimize their own profit, by constantly adjusting their respective demand and playing games with each other until reaching an equilibrium point, which represents the optimal consumption and production strategies for each time period.

After the individual users receive the electricity purchase and sale price from the operator, they formulate the load for each time period and send the optimization results to the information center. The information center is a market information sharing platform, responsible for collecting game information from all parties in the market and providing corresponding information to the users and operator. The user needs to provide the energy consumption strategy to the information center; the information center informs the user of other individuals' strategies for reference in the next round of the game. Therefore, with operator as the leading factor, the Stackelberg master-slave game is established as follows:

$$
S G=\left\{(Z \cup M) ; \boldsymbol{L}_{1}, \ldots, \boldsymbol{L}_{z} ; E U_{1}, \ldots, E U_{z} ; \boldsymbol{P}_{\mathrm{ms}} ; \boldsymbol{P}_{\mathrm{mb}} ; E_{\mathrm{m}}\right\},
$$

where $Z$ and $M$ are the users and the operator, $L_{i}$ is the consumption strategy of user $i$, $\mathrm{y}$ includes the power load in each time period $\left\{l s_{i}^{1}, \ldots, l s_{i}^{H}\right\}, E U_{i}$ is the profit of users as calculated by Equation (21), $\boldsymbol{P}_{\mathrm{ms}}$ and $\boldsymbol{P}_{\mathrm{mb}}$ are the electricity sale price and purchase price strategies of the operator, and $E_{\mathrm{m}}$ is the profit of the operator as expressed in Equation (35).

After the game process converges to an equilibrium solution, neither party in the game can increase profit by changing the strategy [26]. The game can be divided into two levels for coordinative solving. Firstly, the operator optimizes energy purchase strategies as a function of the demand and electricity and gas prices to minimize energy purchase costs.

$$
\begin{aligned}
& \max -F \\
& \text { s.t. } \\
& \left\{\begin{array}{l}
0 \leq \beta \leq 1 \\
0 \leq \theta \leq 1 \\
p_{\text {chp, } \min } \leq \eta_{\mathrm{e}} p_{\mathrm{bh}}^{t} \leq p_{\text {chp, } \max }
\end{array}\right.
\end{aligned}
$$

Then, according to the power grid purchase and sale price, the optimal purchase and sale price for each period is formulated to maximize the transaction profit.

$$
\begin{aligned}
& \max E_{\mathrm{m}} \\
& \text { s.t. } \\
& \left\{\begin{array}{l}
P_{\mathrm{ms}}^{t} \leq P_{\mathrm{gs}}^{t} \\
P_{\mathrm{gb}}^{t} \leq P_{\mathrm{mb}}^{t} \\
0 \leq P_{\mathrm{ms}}^{t}-P_{\mathrm{mb}}^{t}
\end{array}\right.
\end{aligned}
$$

According to the electricity purchase and sale price of the operator and power grid, and the output of PV power, the shiftable load is arranged in each time period to maximize the benefits of each CIES. 


$$
\begin{aligned}
& \max E_{N} \\
& \text { s.t. } \\
& \left\{\begin{array}{l}
l s_{i}^{t *} v_{i, j}^{t}+l s_{j}^{t *} v_{j, i}^{t}=0 \\
\sum_{t=1}^{H} u_{i}^{t}=1 \\
u_{i \min }^{t} \leq u_{i}^{t} \leq u_{\text {max }}^{t}
\end{array}\right.
\end{aligned}
$$

The distributed algorithm is adopted to solve the game model in this paper. The operator layer solves the optimal transaction electricity price and sends the result to the user layer. The user layer determines the optimal energy use plan on the basis of the electricity price result and sends the load adjustment result to the operator layer. This process is repeated with each entity continuously iteratively optimizing their own strategies on the basis of the other's strategies until both parties converge to an equilibrium solution.

\subsubsection{Optimal Operation Strategy for Regional Integrated Energy System}

The CIESs in an RIES are connected with each other through the energy network and the communication network. They realize energy and information sharing via the system network framework.

During the transaction process, CIESs can inform each other of their energy demand and energy sale price through the communication platform and, thus, adjust the trading strategy on the basis of market information with the goal of maximizing their own profit. This process is repeated until a stable strategy value is obtained for the whole RIES and the transaction is completed. Each CIES operator also needs to consider the uncertainty of PV output using the method in Section 3 and maximize the overall profit while meeting the energy demand. Thus, the game model can be described as

$$
\begin{aligned}
& E G=\left\{\begin{array}{l}
(\boldsymbol{M} \cup \boldsymbol{V}) ; \boldsymbol{C}_{1}, \ldots, \boldsymbol{C}_{\mathrm{m}} ; E_{\mathrm{m} 1}, . \\
. ., E_{\mathrm{m} m} ; \boldsymbol{D}_{1}, \ldots, \boldsymbol{D}_{v} ; U_{1}, \ldots, U_{v}
\end{array}\right\}, \\
& \boldsymbol{C}_{i}=\left\{\begin{array}{l}
\left.\boldsymbol{P}_{\mathrm{chp} i} ; \boldsymbol{A}_{i} ; \boldsymbol{B}_{i} ; \boldsymbol{P}_{\mathrm{ms} i} ; \boldsymbol{P}_{\mathrm{mh} i}\right\}
\end{array},\right.
\end{aligned}
$$

where $\boldsymbol{M}$ and $\boldsymbol{V}$ are the CIES operators and "disturbers", $C_{i}$ is the strategy set of CIES operator $i, \boldsymbol{P}_{\mathrm{chp} i}$ is the production planning strategy of CIES operator $i, \boldsymbol{A}_{i}$ and $\boldsymbol{B}_{i}$ are the strategies for electricity purchase/sale and thermal energy planning of CIES operator $i$, $\boldsymbol{P}_{\mathrm{ms} i}$ and $\boldsymbol{P}_{\mathrm{mh} i}$ are the electricity and thermal sale prices of CIES operator $i, E_{\mathrm{m} i}$ is the profit of CIES operator $i, \boldsymbol{D}_{i}$ is the fluctuation value strategy of "disturber" $V_{i}$, and $U i$ is the profit of "disturber" $V_{i}$.

According to a day-ahead negotiation mode, the specific steps of the proposed game are as follows:

Step 1: Each CIES operator plans to purchase and sell energy plans and prices on the basis of their own initial load data and preset values of PV output with the goal of maximizing their own profit;

Step 2: Each game entity announces its own energy sale plan and price through the information network, i.e., the $\boldsymbol{A}, \boldsymbol{B}, \boldsymbol{P}_{\mathrm{ms}}$, and $\boldsymbol{P}_{\mathrm{mh}}$ matrices, and optimizes their own strategy according to public information;

Step 3: On the basis of the optimization result, the "disturber" presents the volatility value strategy using the multi-strategy evolutionary game in Section 3;

Step 4: Each CIES operator re-optimizes the transaction decision according to the PV fluctuation strategy and updates the $\boldsymbol{A}, \boldsymbol{B}, \boldsymbol{P}_{\mathrm{ms}}$, and $\boldsymbol{P}_{\mathrm{mh}}$ matrices;

Step 5: Steps 2 to 4 are repeated until the game reaches the equilibrium solution or the highest game round. 
According to the above, Equation (44) can be written in detail as follows:

$$
\begin{aligned}
& \begin{array}{cc}
\max & E_{\mathrm{mi}}^{t}=P_{\mathrm{ms} i}^{t} \mathbf{e}_{n} \cdot \boldsymbol{A}_{\mathrm{s}, i}^{t} \\
& \left(\boldsymbol{A}_{\mathrm{s}, i}^{t}, \boldsymbol{A}_{\mathrm{b}, i}^{t}, \boldsymbol{B}_{\mathrm{s}, i}^{t}, \boldsymbol{B}_{\mathrm{b}, i}^{t}, P_{\mathrm{msi}}^{t}, P_{\mathrm{mhi} i}^{t}, p_{\mathrm{chpi}}^{t}\right) \\
& -\boldsymbol{P}_{\mathrm{ms} j}^{t} \cdot \boldsymbol{A}_{\mathrm{b}, i}^{t}+P_{\mathrm{mh} i}^{t} \mathbf{e}_{n} \cdot \boldsymbol{B}_{\mathrm{s}, i}^{t}-\boldsymbol{P}_{\mathrm{mh} j}^{t} \cdot \boldsymbol{B}_{\mathrm{b}, i}^{t} \\
& +a_{i} p_{i}^{t}+b_{i}+\alpha_{i} l h_{i}^{t}-\delta_{i}\left(l h_{i}^{t}\right)^{2}-P_{\mathrm{h}}^{t} \frac{p_{\mathrm{chp} i}^{t}}{\eta_{\mathrm{e} i} \mathrm{H}_{\mathrm{hvn}}}
\end{array} \\
& \text { s.t. } \\
& \left\{\begin{array}{l}
p_{\mathrm{u} i}^{t}-p_{\mathrm{chp} i}^{t}-\bar{p}_{\mathrm{PV} i}^{t}-\hat{p}_{\mathrm{PV} i}^{t}= \\
\mathbf{e}_{n} \cdot A_{\mathrm{b}, i}^{t}-\mathbf{e}_{n} \cdot A_{\mathrm{s}, i}^{t}-\mathbf{e}_{n} \cdot \mathbf{L} \mathbf{P}_{i}^{t} \\
l h_{i}^{t}-v_{\mathrm{he}} p_{\mathrm{chp} i}^{t}=\mathbf{e}_{n} \cdot \boldsymbol{B}_{\mathrm{b}, i}^{t-\Delta t}-\mathbf{e}_{n} \cdot \boldsymbol{B}_{\mathrm{s}, i}^{t}-\mathbf{e}_{n} \cdot \mathbf{H P}_{i}^{t} \\
0 \leq a_{\mathrm{b} i, j}^{t} \leq \mathbf{e}_{n} \cdot A_{\mathrm{s}, j}^{t} \\
0 \leq a_{\mathrm{s} i, j}^{t} \leq a_{\mathrm{b} j, i}^{t} \\
0 \leq b_{\mathrm{b} i, j}^{t} \leq \mathbf{e}_{n} \cdot \boldsymbol{B}_{\mathrm{s}, j}^{t} \\
0 \leq b_{\mathrm{s} i, j}^{t} \leq b_{\mathrm{b} j, i}^{t} \\
0 \leq P_{\mathrm{ms} i}^{t} \leq P_{\mathrm{gs}}^{t} \\
0 \leq P_{\mathrm{mh} i}^{t} \leq \frac{p_{\mathrm{h}}^{t}}{\eta_{\mathrm{e} i} \mathrm{H}_{\mathrm{hvn}} v_{\mathrm{he} i}} \\
0 \leq p_{\mathrm{chp} i}^{t} \leq p_{\mathrm{chp} i, \max }^{t}
\end{array}\right.
\end{aligned}
$$

where $A_{\mathrm{s}, i}^{t}$ and $\boldsymbol{B}_{\mathrm{s}, i}^{t}$ are the electricity and thermal energy sale matrices of CIES $i, A_{\mathrm{b}, i}^{t}$ and $\boldsymbol{B}_{\mathrm{b}, i}^{t}$ are the electricity and thermal energy purchase matrices of CIES $i, a_{\mathrm{b} i, j}^{t}, a_{\mathrm{s} i, j}^{t}$ and $b_{\mathrm{b} i, j}^{t}$ $b_{s i, j}^{t}$ are the purchase and sale prices for electricity and thermal energy of CIES $i$ from CIES $j$, $a_{\mathrm{b} j, i}^{t}$ and $b_{\mathrm{b} j, i}^{t}$ are the electricity and thermal purchase plans of CIES $j$ from CIES $i, \mathbf{P}_{\mathrm{ms} j}^{t}$ and $\mathbf{P}_{\text {mhj }}^{t}$ are the electricity and thermal sale prices of other CIESs, $\mathbf{L P}_{i}^{t}$ and $\mathbf{H P}_{i}^{t}$ are the power and thermal losses of CIES $i$ generated by the purchase of electricity and thermal energy, and $\mathbf{e}_{n}$ is the $n$-dimensional unit row vector.

The distributed gradient algorithm is used to solve the problem in this paper. Firstly, CIES $i$ solves Equation (45) to obtain the optimal purchase and sale energy matrices $A_{\mathrm{b}, i}^{t}$, $B_{\mathrm{b}, i}^{t}, A_{\mathrm{s}, i}^{t}$, and $\boldsymbol{B}_{\mathrm{s}, i}^{t}$ as a function of the energy sale price and the purchase and sale plans. Then, each CIES adjusts the sale prices $P_{\mathrm{msi}}^{t}$ and $P_{\mathrm{mh} i}^{t}$ as a function of the adjusted purchase energy matrices $A_{\mathrm{b}, j}^{t}$ and $\boldsymbol{B}_{\mathrm{b}, j}^{t}$ of other CIESs. After that, each CIES operator continuously optimizes their own strategy and then plays the game until reaching the equilibrium point. Finally, the optimal strategy for each CIES operator and the estimated PV fluctuation can be obtained.

\section{Case Study}

\subsection{Case Description}

An RIES consisting of three CIESs is adopted as a case study in this paper [30]. MATLAB R2019a was used on the Windows 10 platform for simulations. Each CIES contained a CHP operator and PV prosumer. The load profiles were reference data from a commercial and residential community on a typical day, where each community included six buildings, and rooftop PV panels range from 100-150 kW. The typical electrical load, thermal load, and distributed PV output profile of a PV prosumer on a certain day are shown in Figure 4 . The total load and PV output of CIES1 from 11:00 a.m. to 4:00 p.m. are shown in Figure 5. The dolphin social network model was selected as the social network model, which contained 62 nodes and 159 edges. The power grid electricity price refers to the time-of-use electricity price standards for commercial users in Beijing, China. The power grid purchase price and gas price were set as the feed-in-tariffs in Beijing, China, which are 0.35 RMB/kWh 
and $1.5 \mathrm{RMB} / \mathrm{m}^{3}$, respectively. The parameters of the CHP in each CIES are shown in Table 1 [30].

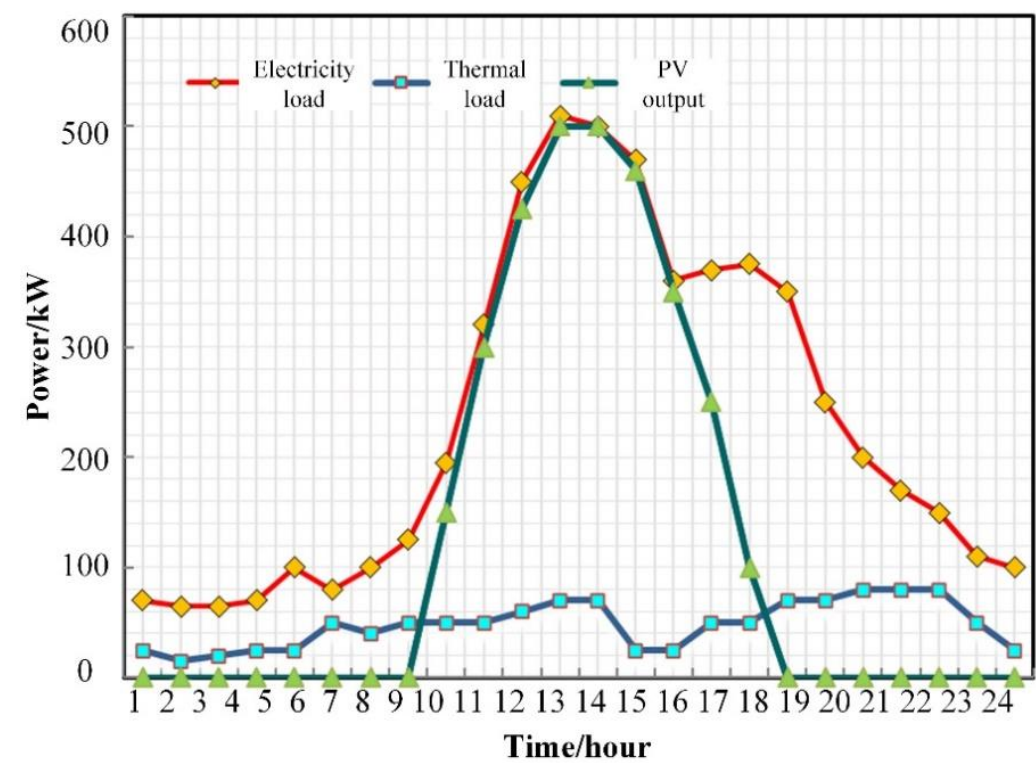

Figure 4. Energy-consumption and PV output curves.

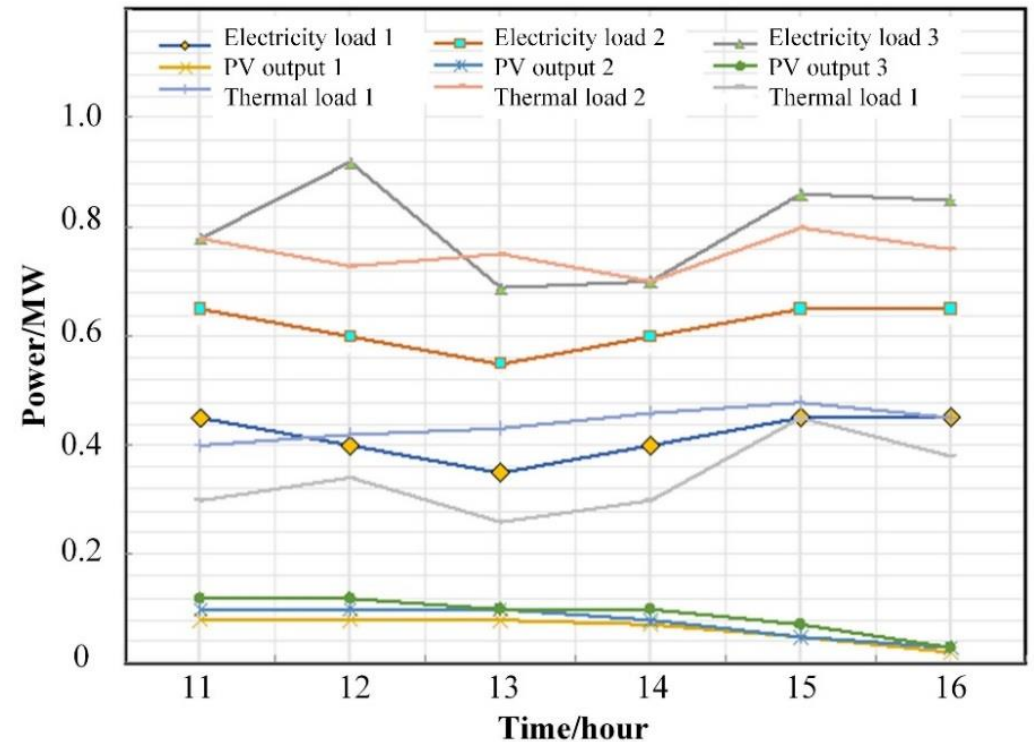

Figure 5. Energy-consumption and PV output curves of each CIES from 11:00 a.m.-4:00 p.m.

Table 1. Relevant parameters for each CIES.

\begin{tabular}{cccccc}
\hline CIES & $\begin{array}{c}\text { CHP Upper } \\
\text { Output/kW }\end{array}$ & $\begin{array}{c}\text { PV } \\
\text { Capacity/kW }\end{array}$ & $\eta_{\mathbf{e}}$ & $\eta_{\text {loss }}$ & $\eta_{\mathbf{h}}$ \\
\hline CIES1 & 300 & 100 & 0.35 & & 0.6 \\
CIES2 & 900 & 200 & 0.40 & 0.05 & 0.6 \\
CIES3 & 700 & 150 & 0.35 & & 0.8 \\
\hline
\end{tabular}

\subsection{Results and Discussion}

\subsubsection{Energy-Consumption Pattern Analysis}

Using the characteristic model for community energy-consuming entities proposed in Section 3, the alliance result of energy-consuming entities is shown in Figure 6. 


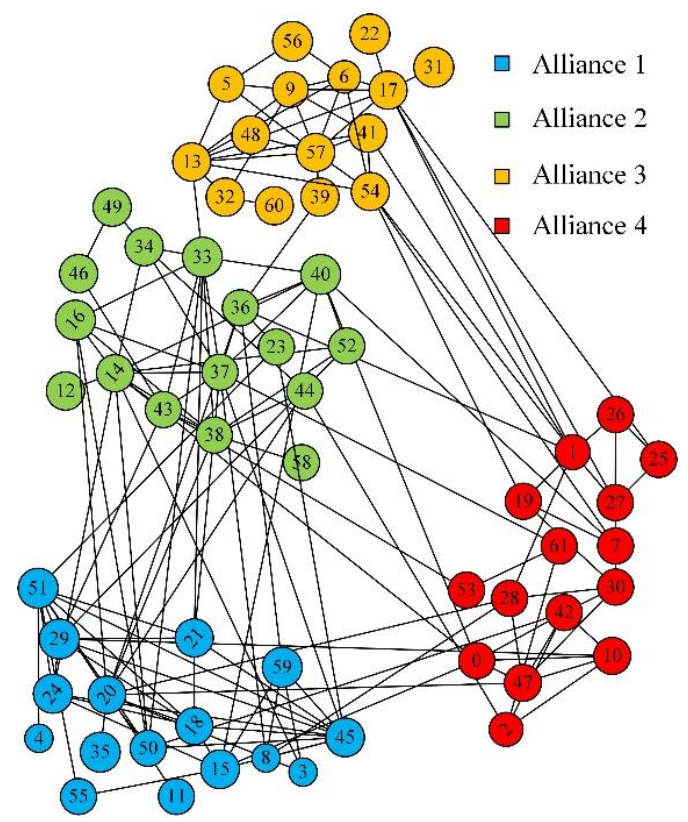

Figure 6. Alliance result of energy consuming entity.

The 62 energy-consuming entities formed four trading alliances, indicating that the maximum modularity $Q$ was reached when the number of alliances was 4 . Taking Alliance 3 as an example, by calculating the user potential influence and user similarity, users 5 , $6,9,13,17,22,31,32,39,41,48,54,56,57$, and 60 can be considered similar. Users in the same community are regarded as an energy transaction whole, whereby all users share the photovoltaic output and adjust the load in each period to maximize the overall income of the alliance. Alliances 1-4 contained 16, 16, 15, and 15 entities, respectively, according to the familiarity of trading strategies and the similarity of energy-using behavior between each user. On the basis of the alliance results, the solution method in Section 4.5 was used to obtain the optimized electricity price, as shown in Figure 7 . The electricity sale price of the operator in each period was lower than the price of power grid, which was more obvious from 10:00 a.m. to 2:00 p.m. This is the peak period where PV output met the local load demand. When PV output was reduced after 5:00 p.m., the energy purchase cost of the operator began to increase, thereby increasing the energy sale profit along with electricity prices.

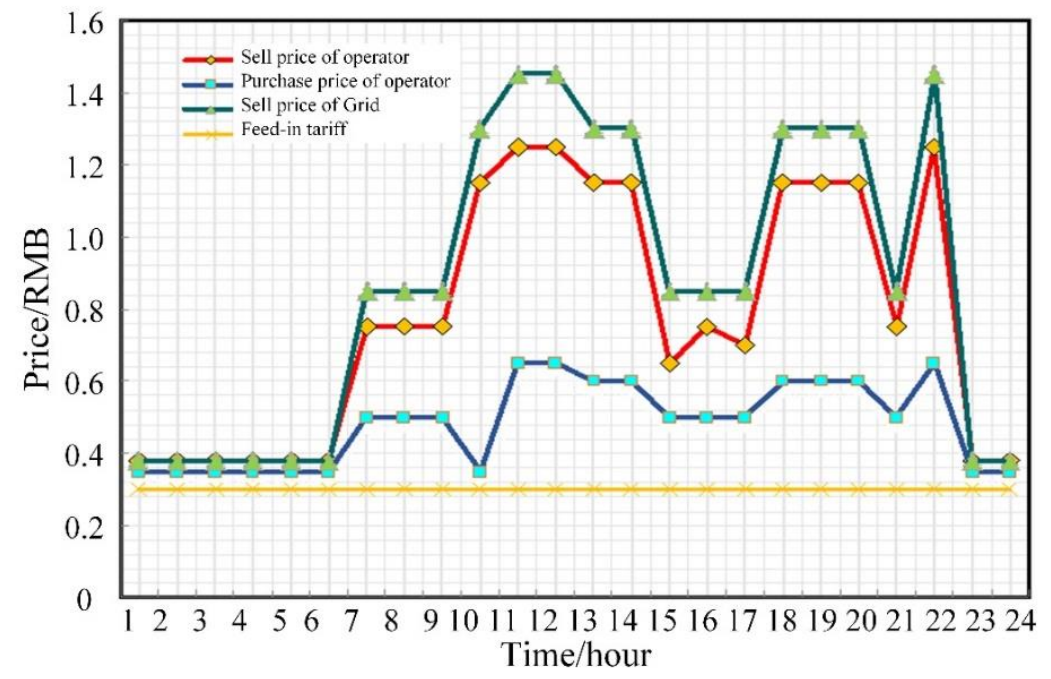

Figure 7. Price profile. 
The user load optimization results are shown in Figure 8. By participating in market transactions, the peak load was reduced after optimization. The power consumption during the valley period (12:00-8:00 a.m.) increased, while the power consumption during the peak period (3:00-5:00 p.m.) decreased significantly. According to the optimization result of the operator's energy purchase scheduling coefficient shown in Figure 9, when the surplus power load was low, it was more economical to purchase electrical energy to convert into thermal energy; hence, the P2G dispatch coefficient was relatively high, as especially obvious from 9:00 a.m.-1:00 p.m. The surplus load was relatively high from 5:00-6:00 p.m., which could be converted into electrical energy by purchasing gas to reduce costs. Therefore, the thermal-to-electricity dispatch coefficient was relatively high.

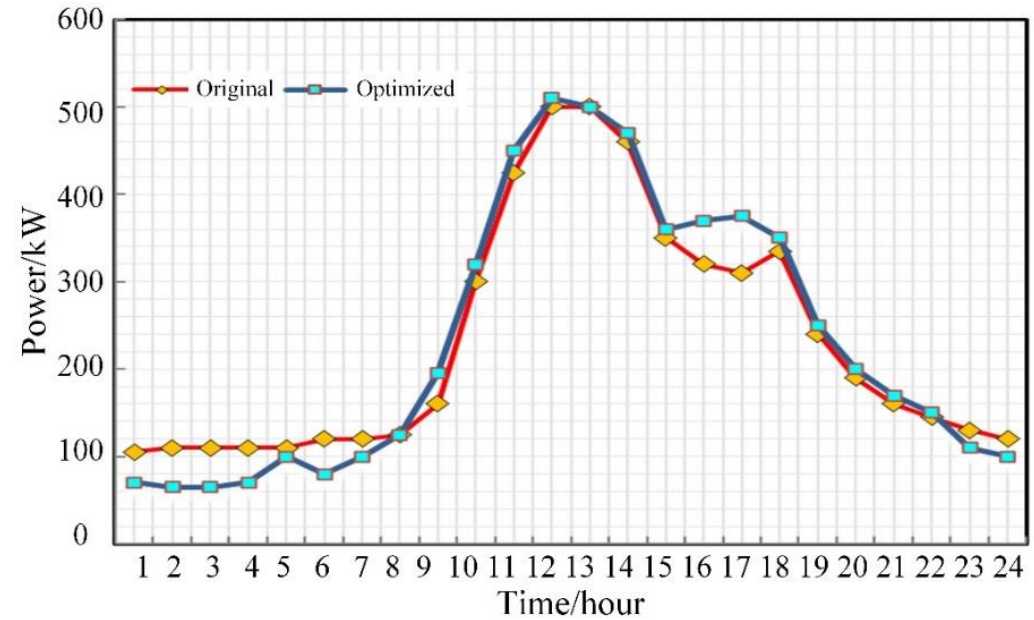

Figure 8. Optimized load profile.

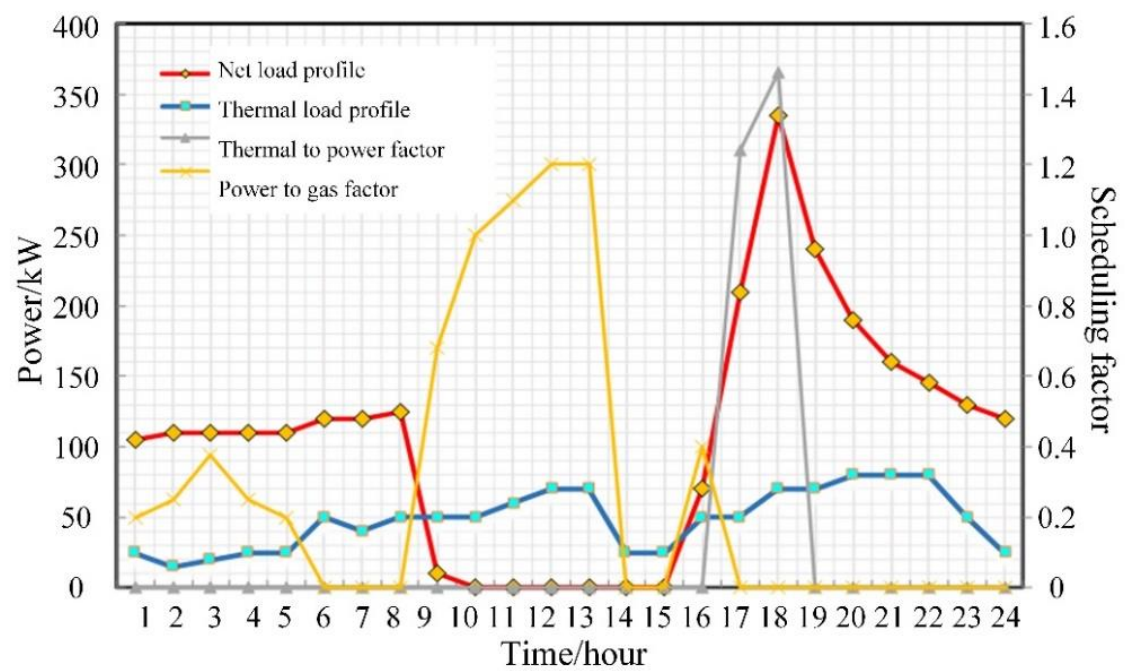

Figure 9. Scheduling results.

The profit results of the operator and user alliances are shown in Figure 10. The total profit of the operator was 807.5 RMB, and the profits of user alliances 1-4 were 3124.6, 3218.7, 2905.4, and 3001.1 RMB, respectively. The results show that users could realize shiftable load transfer through alliances, thereby absorbing surplus PV output and reducing electricity purchase costs. Thus, users could increase their own profits, while reducing the operator's profit. To study the impact of different user social network parameters on the community energy transaction market, we compared the energy transaction results of community users under several different social network models. The results of alliances and transaction gains under different circumstances are shown in Table 2. 


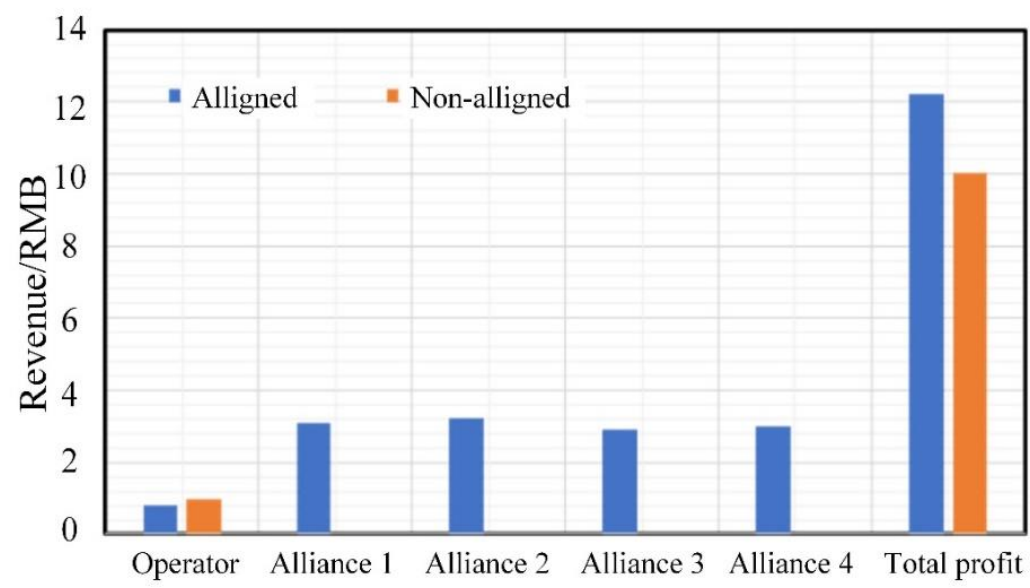

Figure 10. Transaction profit.

Table 2. Transaction profit under different social network structure parameters.

\begin{tabular}{cccc}
\hline Number of Alliances & $\begin{array}{c}\text { Energy-Consuming } \\
\text { Entity Profit (RMB) }\end{array}$ & $\begin{array}{c}\text { CIES Operator Profit } \\
\text { (RMB) }\end{array}$ & $\begin{array}{c}\text { RIES Total Profit } \\
\text { (RMB) }\end{array}$ \\
\hline 2 & $13,732.6$ & 683.7 & $14,416.3$ \\
4 & $12,249.8$ & 807.5 & $13,057.3$ \\
10 & $11,603.2$ & 915.2 & $12,518.4$ \\
20 & $10,316.1$ & 1004.5 & $11,320.6$ \\
\hline
\end{tabular}

Obviously, it can be seen that stronger user aggregation and a smaller number of alliances led to higher user profit and lower operator profit, but a higher total profit of the CIES. Therefore, a closer social relationship between users and a higher familiarity in the CIES yield greater social benefits of the system under this energy transaction mode. On the contrary, the user profit would decrease, while the operator profit would increase, thus reducing the overall social benefits.

\subsubsection{Photovoltaic Output Fluctuation Analysis}

The preset typical daily PV output was used as the benchmark, and the predicted value of the PV output of each CIES operator in each time period was obtained using the proposed characteristic model of distributed photovoltaic output. The internal evolution process of the PV fluctuation strategy in each CIES at 12:00 p.m. is shown in Figures 11-13 as an example. The estimated value of PV output and actual output from 11:00 a.m.-4:00 p.m. of each CIES is shown in Figures 14-16.

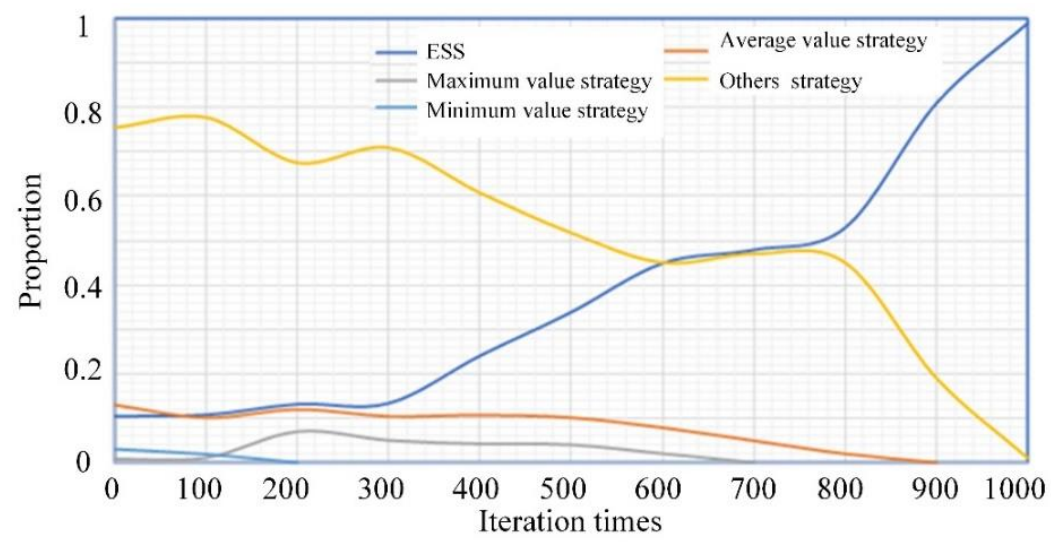

Figure 11. Strategy evolution process of PV fluctuation in CIES1. 


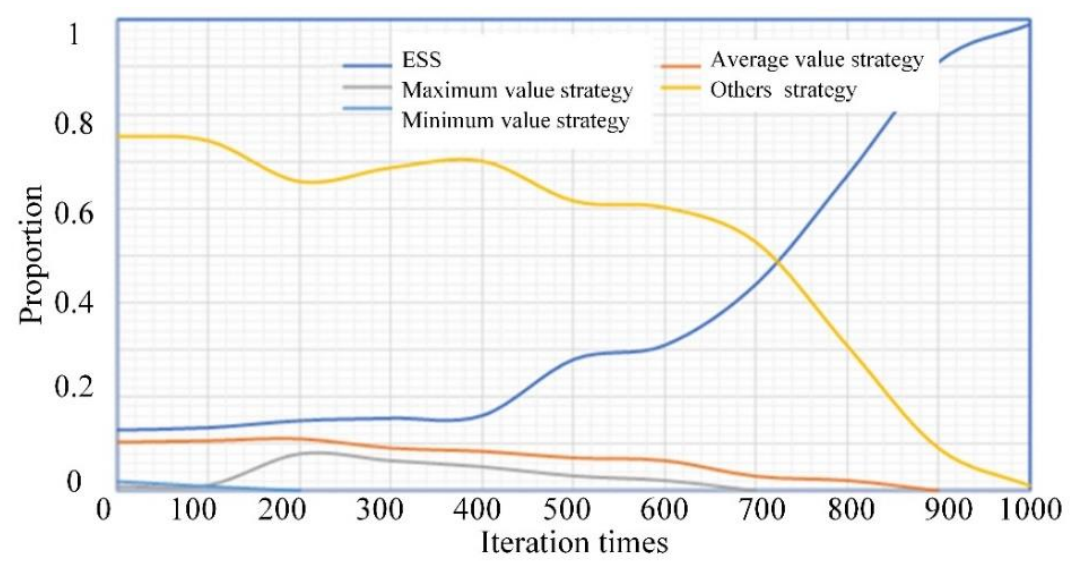

Figure 12. Strategy evolution process of PV fluctuation in CIES2.

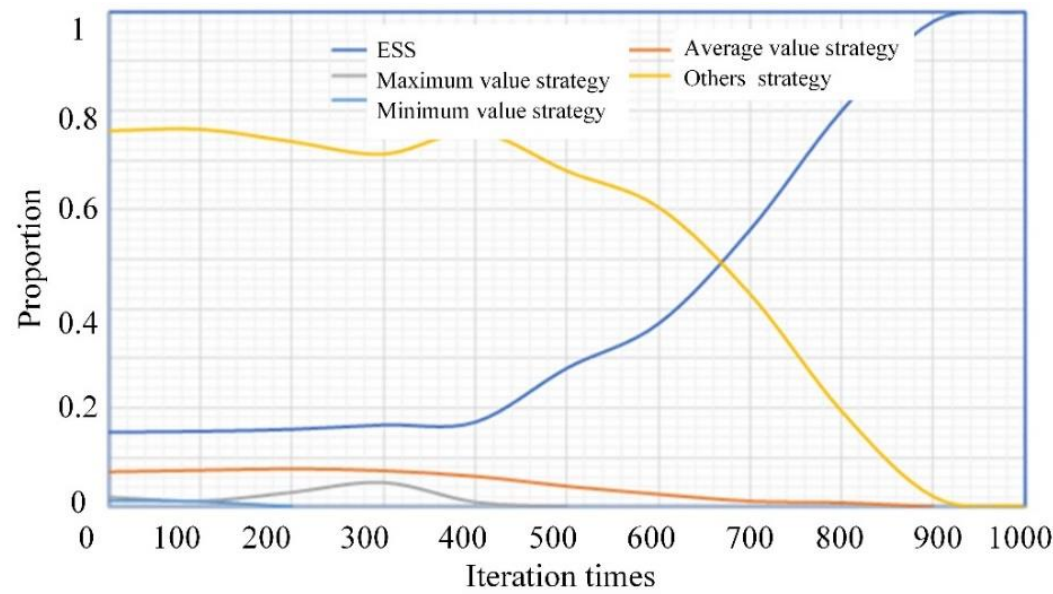

Figure 13. Strategy evolution process of PV fluctuation in CIES3.

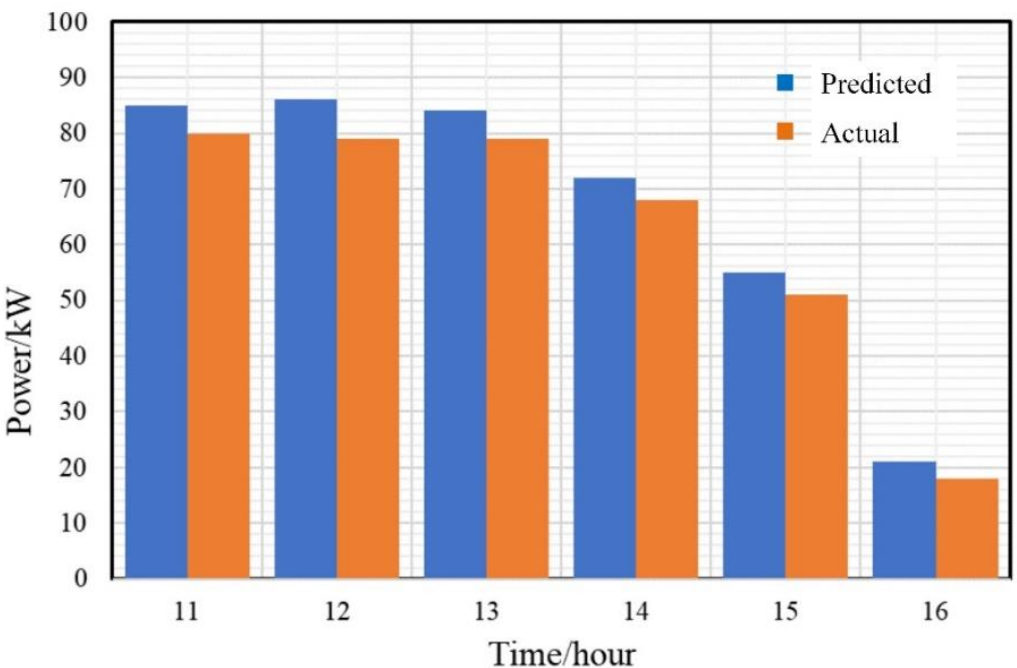

Figure 14. PV output of CIES1 from 11:00 a.m.-4:00 p.m. 


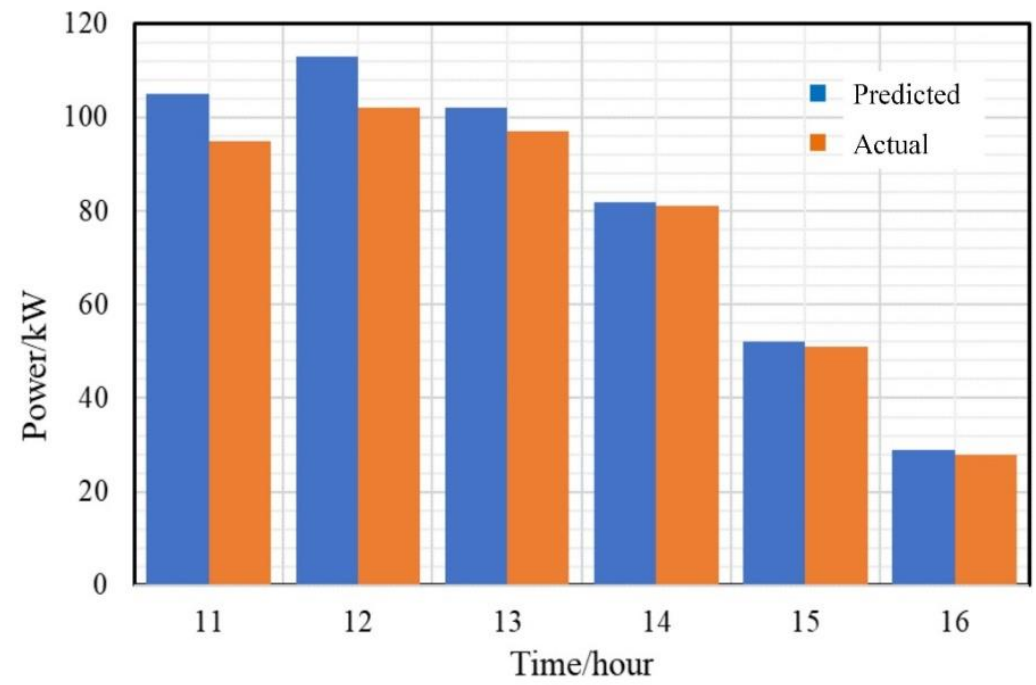

Figure 15. PV output of CIES2 from 11:00 a.m.-4:00 p.m.

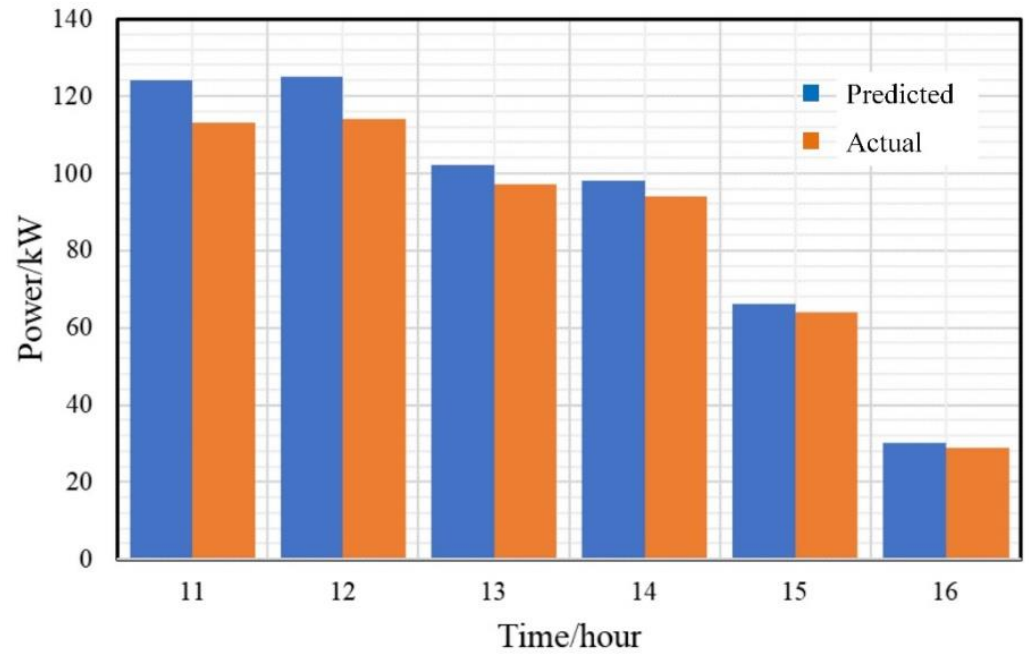

Figure 16. PV output of CIES3 from 11:00 a.m.-4:00 p.m.

The stable evolution strategy of the PV fluctuation value was neither the lowest nor the highest value of fluctuation, indicating that the probability distribution and return function of each fluctuation value strategy had an impact on the dynamic game process in the evolutionary game model. The final individual selection in the population evolved to a stable strategy with the highest adaptability. Meanwhile, the different parameters of PV installations in each CIESs caused the actual value and estimated value of PV output to differ between each CIES. The root-mean-square deviations of CIESs 1-3 were $4.831 \mathrm{~kW}$, $6.442 \mathrm{~kW}$, and $6.928 \mathrm{~kW}$, respectively. The overall deviation of the estimated value was slightly higher when the PV output capacity was large. Each subject in the uncertainty game model chose a conservative strategy, and the estimated value of each group was generally lower than the actual output. This shows that the participants in the game could avoid the losses caused by PV fluctuation by adopting the uncertain evolutionary game method.

\section{Conclusions}

From the perspective of the energy consumer sociality and the power output uncertainty, this paper analyzed the main characteristics of the source- and load-side entities in an RIES. An optimized operation strategy was proposed for an RIES considering the entity characteristics of the demand and supply side. The results show that a closer social 
relationship between users in the community leads to a higher overall profit of RIES energy transactions. By considering the impact of PV output uncertainty, the transaction risk cost of the supply-side entities can be reduced, and the overall system profit level and operational efficiency can be improved.

The proposed method can provide guidance for community-level energy trading to achieve overall operating efficiency improvement. Further research will be conducted on the reasonable profit distribution among different investment entities.

Author Contributions: Conceptualization, M.T.; methodology, W.L.; validation, W.L. and X.Z.; writing—original draft preparation, X.Z.; writing—review and editing, D.G. and J.W. All authors have read and agreed to the published version of the manuscript.

Funding: This research received no external funding.

Conflicts of Interest: The authors declare no conflict of interest.

\section{References}

1. Li, J.; Liu, J.; Yan, P.; Li, X.; Zhou, G.; Yu, D. Operation optimization of integrated energy system under a renewable energy dominated future scene considering both independence and benefit: A review. Energies 2021, 14, 1103. [CrossRef]

2. Yousaf, A.; Asif, R.M.; Shakir, M.; Rehman, A.U.; Adrees, M.S. An improved residential electricity load forecasting using a machine-learning-based feature selection approach and a proposed integration strategy. Sustainability 2021, 13, 6199. [CrossRef]

3. Satymov, R.; Bogdanov, D.; Breyer, C. The Value of Fast Transitioning to a Fully Sustainable Energy System: The Case of Turkmenistan. IEEE Access 2021, 9, 13590-13611. [CrossRef]

4. Rizwan, R.; Arshad, J.; Almogren, A.; Jaffery, M.H.; Yousaf, A.; Khan, A.; Ur Rehman, A.; Shafiq, M. Implementation of ANNbased embedded hybrid power filter using hil-topology with real-time data visualization through node-RED. Energies 2021, 14, 7127. [CrossRef]

5. Zeng, A.; Hao, S.; Ning, J.; Xu, Q.; Jiang, L. Research on real-time optimized operation and dispatching strategy for integrated energy system based on error correction. Energies 2020, 13, 2908. [CrossRef]

6. Li, Z.; Xu, Y.; Fang, S.; Wang, Y.; Zheng, X. Multiobjective Coordinated Energy Dispatch and Voyage Scheduling for a Multienergy Ship Microgrid. IEEE Trans. Ind. Appl. 2020, 56, 989-999. [CrossRef]

7. Alobaidi, A.H.; Khodayar, M.E.; Shahidehpour, M. Decentralized energy management for unbalanced networked microgrids with uncertainty. IET Gener. Transm. Distrib. 2021, 15, 1922-1938. [CrossRef]

8. Xu, Y.; Liao, Q.; Liu, D.; Peng, S.; Yang, Z.; Zou, H.; Zhang, L. Multi-player Intraday Optimal Dispatch of Integrated Energy System Based on Integrated Demand Response and Games. Power Syst. Technol. 2019, 43, 2506-2516.

9. Li, H.; Yu, T.; Qu, K.; Wang, B. Interactive Equilibrium Supply and Demand Model for Electricity-Gas Energy Distribution System with Participation of Integrated Load Aggregators. Autom. Electr. Power Syst. 2019, 43, 32-41.

10. Liu, W.; Li, X.; Liu, Z.; Wang, K.; Wang, W. Energy operator operating mode and energy management based on Stackelberg game. Mod. Electr. Power 2018, 35, 8-15.

11. Soliman, H.M.; Leon-Garcia, A. Game-theoretic demand-side management with storage devices for the future smart grid. IEEE Trans. Smart Grid 2014, 5, 1475-1485. [CrossRef]

12. Chai, B.; Chen, J.; Yang, Z.; Zhang, Y. Demand response management with multiple utility companies: A two-level game approach. IEEE Trans. Smart Grid 2014, 5, 722-731. [CrossRef]

13. Wu, C.; Gao, B.; Tang, Y.; Wang, Q. Master-slave game based bilateral contract transaction model for generation companies and large consumers. Autom. Electr. Power Syst. 2016, 40, 56-62.

14. Li, H.; Yu, T.; Zhu, H.; Chen, Y.; Yang, B. Interactive Equilibrium of Electricity-Gas Energy Distribution System and Integrated Load Aggregators Considering Energy Pricings: A Master-Slave Approach. IEEE Access 2020, 8, 70527-70541. [CrossRef]

15. Gu, J.; Bai, K.; Shi, Y. Optimized Operation of Regional Integrated Energy System Based on Multi-agent Master-slave Game Optimization Interaction Mechanism. Power Syst. Technol. 2019, 43, 3119-3129.

16. Li, Y.; Wang, C.; Li, G.; Chen, C. Optimal scheduling of integrated demand response-enabled integrated energy systems with uncertain renewable generations: A Stackelberg game approach. Energy Convers. Manag. 2021, 235, 113996. [CrossRef]

17. Ma, L.; Liu, N.; Zhang, J.; Lei, J.; Zeng, Z.; Liu, W. Optimal operation model of user group with photovoltaic in the mode of automatic demand response. Proc. Chin. Soc. Electr. Eng. 2016, 36, 3422-3432.

18. Derakhshandeh, S.Y.; Masoum, A.S.; Deilami, S.; Masoum, M.A.S.; Hamedani Golshan, M.E. Coordination of generation scheduling with PEVs charging in industrial microgrids. IEEE Trans. Power Syst. 2013, 28, 3451-3461. [CrossRef]

19. Ma, Z.; Zhou, X.; Shang, Y.; Sheng, W. Exploring the concept, key technologies and development model of energy internet. Power Syst. Technol. 2015, 39, 3014-3022.

20. Liu, F.; Pan, Y.; Liu, H.; Ding, Q.; Li, Q.; Wang, Z. Piecewise exponential distribution model of wind power forecasting error. Autom. Electr. Power Syst. 2013, 37, 14-19. 
21. Huo, S. Optimization Method of Source Load Coordinated Operation of Active Distribution Network Considering Source Load Uncertainty; Nanjing University of Posts and Telecommunications: Nanjing, China, 2019.

22. Zhou, Y.; Yang, M.; Wang, F.; Wang, S.; Zhu, Y. A real-time dispatch model considering the uncertainty in Photovoltaic power. Electr. Power Constr. 2019, 40, 1-8.

23. Kang, C.; Yao, L. Key scientific issues and theoretical research framework for power systems with high proportion of renewable energy. Autom. Electr. Power Syst. 2017, 41, 2-11.

24. Jian, X.; You, J.; Liang, Y.; Jia, L. Social influence based close subgraph discovery in social networks. J. Chin. Comput. Syst. 2018, $39,1342-1348$.

25. Yin, X.; Hu, X.; Chen, Y.; Yuan, X.; Li, B. Signed-PageRank: An efficient influence maximization framework for signed social networks. IEEE Trans. Knowl. Data Eng. 2021, 33, 2208-2222. [CrossRef]

26. Liu, N.; Chen, Q.; Liu, J.; Lu, X.; Li, P.; Lei, J.; Zhang, J. A heuristic operation strategy for commercial building microgrids containing EVs and PV system. IEEE Trans. Ind. Electron. 2015, 62, 2560-2570. [CrossRef]

27. Ting, C.; Samdin, S.B.; Tang, M.; Ombao, H. Detecting dynamic community structure in functional brain networks across individuals: A multilayer approach. IEEE Trans. Med. Imaging 2021, 40, 468-480. [CrossRef]

28. Huang, N.; Bao, J.; Cai, G.; Zhao, S.; Liu, D.; Wang, J.; Wang, P. Multi-agent joint investment microgrid source-storage multistrategy bounded rational decision evolution game capacity planning. Proc. Chin. Soc. Electr. Eng. 2020, 40, $1212-1225$.

29. Lee, D.; Jeong, J.; Choi, G. Short term prediction of PV power output generation using hierarchical probabilistic model. Energies 2021, 14, 2822. [CrossRef]

30. Wei, Z.; Liu, L.; Guan, X. Research on Community-Based Energy Internet Operation Considering the Relationship Between Social Networks. Electr. Power Constr. 2019, 40, 36-44. 